\title{
Sentimentos partidários e antipetismo: condicionantes e covariantes
}

$\begin{array}{r}\text { Ednaldo Ribeiro } \\ \text { Yan Carreirão } \\ \text { Julian Borba } \\ \hline\end{array}$

\section{Introdução ${ }^{1}$}

São bem conhecidos na literatura brasileira os principais aspectos do debate internacional sobre identificação partidária, especialmente a discussão sobre como se origina essa identificação, sua relação com as atitudes e o comportamento dos eleitores e a tendência de declínio da identificação partidária em boa parte das democracias ocidentais nas últimas décadas. Além disso, há já uma significativa produção empírica no Brasil, analisando o perfil do eleitor com identificação partidária, a evolução dessa identificação ao longo do tempo, as atitudes associadas aos eleitores identificados com diferentes partidos e o impacto dessa identificação sobre a decisão de voto (Lamounier e Meneguello, 1986; Singer, 2000; Reis, 2000; Mainwaring, 1991; Rennó, 2007; Paiva, Braga e Pimentel Jr., 2007; Carreirão, 2007b; Ribeiro, Carreirão e Borba, 2011; Braga e Pimentel Jr., 2011; Neves, 2012; Speck, Braga e Costa, 2015; Baker et al., 2016).

Bem menos desenvolvida no país é a discussão sobre identificação partidária negativa (ou sentimentos partidários negativos). Um dos objetivos deste artigo é justamente dar destaque a esse tema, inicialmente resenhando parte da literatura internacional e também da produção brasileira, que, embora incipiente, existe e tem se ampliado no período mais recente, especialmente em função do fenômeno que tem sido chamado de antipetismo. Empiricamente, também, este artigo dará ênfase aos sentimentos partidários negativos, especialmente ao antipetismo. Fazemos isso de forma longitudinal, ainda que a série histórica de dados utilizada não seja longa (de 2002 a 2014), procurando identificar mudanças significativas nos perfis desse público específico que podemos denominar de antipetista. Além disso, investigamos a relevância desses sentimentos sobre disposições subjetivas em relação a temas relevantes como adesão à democracia, preferência por democracia, igualitarismo e estatismo. Por fim, testamos também a relevância dessa condição no processo de escolha de candidatos nas eleições presidenciais.

\footnotetext{
${ }^{1}$ Este artigo é fruto de pesquisas apoiadas pelo Conselho Nacional de Desenvolvimento Científico e Tecnológico (CNPq), através de bolsas de produtividade e de iniciação científica. Os autores agradecem aos pareceristas anônimos pelas críticas e sugestões.
} 
Isso não significa, porém, que deixamos de analisar a identificação partidária (positiva) dos eleitores. Retomando proposta anterior (Ribeiro, Carreirão e Borba, 2011), além de tratar dos efeitos específicos do antipetismo, analisamos também o impacto simultâneo das identificações partidárias positivas e negativas em relação ao PT e ao PSDB (os dois principais partidos nessa disputa) sobre o voto nas eleições brasileiras de 2014, usando dados do Eseb (Estudo Eleitoral Brasileiro) ${ }^{2}$.

A principal hipótese do artigo é que o contexto político do país em 2014, em que o PT esteve fortemente associado a escândalos de corrupção, afetou os sentimentos partidários positivos e negativos em relação ao partido. Quanto aos sentimentos positivos, provocando um declínio dos identificados com o partido; e, quanto aos negativos, levando a um acréscimo nos "antipetistas". Essas mudanças nos sentimentos partidários tiveram impacto tanto sobre as atitudes quanto no comportamento político do eleitorado em 2014. Em termos de atitudes, ampliando o quadro de não diferenciação do eleitorado, já constatado em períodos anteriores (Carreirão, 2007a; Ribeiro, Carreirão e Borba, 2011). Já no plano comportamental, espera-se que tanto os sentimentos positivos quanto os negativos estejam relacionados ao voto, e que a ampliação do antipetismo tenha favorecido os candidatos de oposição.

\section{Identificação partidária}

O debate entre a Escola de Michigan (Campbell et al., 1960; Converse, 1964) e a teoria da escolha racional (Downs, 1957; Fiorina, 1981) sobre como se originam as identificações partidárias e qual seu significado já é bastante conhecido entre nós (Figueiredo, 1991; Castro, 1992; Carreirão e Kinzo, 2004; Pimentel Jr., 2007; Ribeiro, Carreirão e Borba, 2011, entre outros). Independentemente dessa discussão, até bem pouco tempo atrás havia um alto grau de consenso sobre a importância das identificações partidárias dos eleitores sobre sua decisão de voto.

Nas últimas décadas, porém, assiste-se, no plano internacional, a um declínio nos níveis de identificação, na diferenciação ideológica entre os partidos, bem como na relevância dessas organizações em termos de estruturação da decisão do voto (Wattenberg, 1991, 1998; Dalton e Wattenberg, 1993, 2001; Clarke e Stewart, 1998), tema que também já é bastante conhecido no país.

Em relação ao caso brasileiro, em balanço feito em artigo anterior (Ribeiro, Carreirão e Borba, 2011), mostramos que após certo predomínio de uma avaliação negativa quanto aos níveis de identificação partidária e de sua influência sobre o voto (Lamounier e Meneguello, 1986; Mainwaring, 1991, 2001), o estudo de Singer (2000) representou uma mudança nessa interpretação ao apontar para a importância das identificações ideológicas e partidárias dos eleitores brasileiros na estruturação do voto

\footnotetext{
2 Algumas das análises aqui empreendidas buscam traçar uma evolução dos sentimentos partidários dos brasileiros entre 2002 e 2014 (sempre usando o Eseb), embora a ênfase seja sobre os dados de 2014.
} 
nas eleições de 1989 e 1994, tendo sido refutado por investigações posteriores (Reis, 2000; Rennó, 2007; Paiva, Braga e Pimentel Jr., 2007), mas também parcialmente confirmado por outros trabalhos (Carreirão, 2007b; Braga e Pimentel Jr., 2011).

Mais recentemente, as conclusões de Braga e Pimentel Jr. (2011), Neves (2012), Speck, Braga e Costa (2015) e Baker et al. (2016) confirmam, embora com certas especificidades, a relevância da identificação (ou simpatia) partidária na estruturação das atitudes e/ou do comportamento do eleitorado brasileiro.

Braga e Pimentel Jr. (2011), analisando dados dos Esebs 2002, 2006 e 2010, propõem que,

apesar de as simpatias partidárias serem uma heurística utilizada para decisão do voto entre os eleitores com maior escolaridade, foi observado que mesmo entre os menos escolarizados esse elemento foi fundamental para explicar o voto, demonstrando que, mesmo entre eleitores com menor conhecimento político, os partidos, especialmente PT, PSDB e PMDB, têm balizado a decisão do voto (Braga e Pimentel Jr., 2011, p. 298).

O estudo de Neves (2012) - que analisa os efeitos de atitudes positivas e contrárias aos principais partidos (PT, PSDB e PMDB) sobre o voto nas eleições de 2002, 2006 e 2010 - reforça a relevância dessas disposições, ainda que a magnitude dos seus efeitos sofra variação ao longo do período. Em 2002 e 2010 o autor observa expressiva influência das identidades partidárias, principalmente em relação às legendas PT e PSDB e suas respectivas coligações, mas em 2006 esse efeito diminui de forma considerável, provavelmente em decorrência da influência de aspectos conjunturais, como o quadro de reeleição e a presença de um candidato de alta popularidade. Speck, Braga e Costa (2015), embora não destaquem as diferenças entre as legendas, também constatam que a identificação partidária está associada à adoção de padrões coerentes de votação em candidatos da mesma sigla para diferentes cargos.

Quanto à estabilidade das preferências partidárias, Baker et al. (2016), analisando dados de um estudo de painel em Juiz de Fora e Caxias do Sul, buscam verificar se a mudança na "marca PT" (brand change) entre 2002 e 2006 teria feito muitos eleitores petistas deixarem de manifestar simpatia pelo partido. Sua principal conclusão é a de que isso ocorreu com parte dos "petistas ocasionais", mas um núcleo duro de petistas (de cerca de 40\%) continuou manifestando preferência pelo partido, durante todo o período do painel: "bounded instability exists around a core of stability" (Baker et al., 2016, p. 27).

Não há, porém, consenso na literatura. Pereira (2014b), analisando dados das mesmas pesquisas de opinião em painel $^{3}$ e enfatizando a relevância da sofisticação política dos eleitores para a formação de identidades partidárias duradouras, conclui que:

\footnotetext{
${ }^{3}$ A pesquisa foi a mesma utilizada por Baker et al. (2016) - "The dynamics of political attitude formation in a milieu of multiple weak parties: a context sensitive analysis of voting behavior in two Brazilian cities" 
Os menos sofisticados tendem a formar essa preferência com base em estímulos mais transitórios do ambiente eleitoral, e não em percepções quanto a questões políticas mais centrais que atravessam o sistema partidário (...). Como é baseada em estímulos passageiros, tal preferência tende a desaparecer mais facilmente e a não afetar outras preferências políticas importantes que o cidadão é chamado a manifestar (Pereira, 2014b, p. 239).

Como corolário, afirma que "a correlação agregada entre partidarismo e voto no Brasil esconde o fato de que a segunda variável só é determinada pela primeira, de fato, para uma minoria politicamente sofisticada de eleitores" (Pereira, 2014b, p. 238) ${ }^{4}$.

Para além dessa polêmica, uma série de trabalhos tem investigado as bases sociais dos partidos, enfatizando mais as identificações partidárias do que o voto, bem como as opiniões e atitudes políticas dos eleitores e sua relação com os sentimentos partidários. Um tema que tem sido objeto central de discussão é relativo às bases sociais do petismo. Enquanto Samuels $(2004,2008)$ observa poucas mudanças nesse eleitorado identificado com o partido ao comparar os resultados de surveys realizados em 2002 e 2007, tanto Singer (2010) quanto Venturi (2010) apontam mudanças no perfil socioeconômico dos eleitores com preferência pelo PT. Segundo esses últimos autores, comparativamente ao período inicial do atual sistema partidário, em anos mais recentes diminuiu a importância dos eleitores de mais alta escolaridade, de mais alta renda e da região Sudeste. Veiga $(2007,2011)$, da mesma forma, comparando dados da coleção Eseb para 2002, 2006 e 2010, aponta para mudanças nas bases de identificação partidária, em especial em relação ao PT, que se deslocou para um eleitorado de menor renda e menor escolaridade, aumentando suas bases especialmente no Nordeste.

Paralelamente às mudanças nas bases sociais, também se discutem as mudanças no perfil ideológico dos eleitores partidários. Segundo Veiga, essa mudança de base social poderia ser uma das razões que explicariam o deslocamento ao centro e à direita daqueles que se identificam com o PT. Também Singer (2010) explora as contradições entre duas matrizes ideológicas e programáticas que convivem no partido e, comparando resultados de surveys realizados entre 2002 e 2010, conclui que "a base do PT, que era predominantemente de esquerda, passou a abrigar um contingente análogo de eleitores situados à direita" (p. 108).

(Baker et al., 2016) - e realizou ondas de entrevistas em abril/maio; agosto/setembro e outubro de 2002; maio de 2004; julho e outubro de 2006 nas cidades brasileiras de Juiz de Fora (MG) e Caxias do Sul (RS).

${ }^{4}$ Embora essas conclusões tenham se baseado em análise focalizando apenas os eleitores que declaram ter preferência pelo PT, Pereira sugere - tomando como base estudo de Samuels, que fornece evidências de que a preferência pelos demais partidos brasileiros tende a ser ainda mais fraca e guiada por vínculos personalistas - que os achados de seu trabalho seriam "ainda menos otimistas com a inclusão de eleitores que se identificam com outros partidos" (Pereira, 2014b, p. 239). 
Outros estudos incluem os demais partidos relevantes em suas análises. Veiga (2007), além das conclusões já mencionadas sobre o PT, indica que o PMDB teria ampliado sua base entre os eleitores de maior escolaridade e da região Sul, deslocandose para a esquerda na autolocalização ideológica. Por fim, PSDB e PFL (atual DEM) teriam experimentado mudanças menores em termos de bases sociais. Carreirão (2008), por sua vez, tomando como base empírica quatro surveys realizados em 1990, 1997, 2002 e 2007, conclui que as opiniões políticas dos eleitores que manifestavam sentimentos por diferentes partidos eram mais diferenciadas entre si em 1990 do que em 2007. Entre os elementos que embasam essa conclusão está o fato de que os "eleitores petistas" e os "eleitores peessedebistas" vão se tornando progressivamente indiferenciados do conjunto do eleitorado quanto ao posicionamento ideológico (Carreirão, 2008, p. 339). Sobre a relação entre os sentimentos nutridos pelos eleitores em relação aos partidos e algumas dimensões atitudinais, o já citado trabalho de Speck, Braga e Costa (2015) encontra que a identificação está associada a maior conhecimento político e maior intensidade no associativismo.

O conjunto desses trabalhos aponta para campos de discussão ainda abertos no que diz respeito à composição dos perfis sociodemográficos da identificação em geral e das identificações específicas com as legendas centrais, mas também sobre seus covariantes atitudinais e comportamentais, especialmente no que diz respeito à dimensão eleitoral. O presente artigo pretende contribuir para essa discussão, entretanto, focalizando mais o que Rose e Mishler (1998) chamam de "outro lado da moeda" da identificação: a rejeição ou sentimentos negativos em relação aos partidos. Mais especificamente, considerando a relevância do PT no cenário político nacional recente, nos concentramos sobre a identificação das bases sociais e dos covariantes dos sentimentos negativos em relação a essa legenda. Antes de passar à análise dos dados, segue uma revisão da literatura internacional e nacional sobre identificação partidária negativa (ou sentimentos partidários negativos) ${ }^{5}$.

\section{Identificação partidária negativa}

O tema da identificação entre eleitores e partidos políticos tem uma longa história na ciência política. Independentemente das suas bases, os estudos sobre identificação partem de uma afirmação básica sobre a sua relevância para a explicação da durabilidade e persistência de partidos e sistemas partidários. A aceitação dessa relevância, porém, coloca a necessidade de atribuição de importância para o seu oposto, ou seja, a rejeição a uma ou mais legendas. Embora a identificação negativa já estivesse

\footnotetext{
${ }^{5}$ Salvo engano, o trabalho recente de Zucco e Samuels (2015) é o primeiro relativo ao Brasil a chamar a atenção para o debate teórico na literatura internacional sobre o tema da "identificação partidária negativa". Daí a importância de ampliar a revisão dessa literatura.
} 
presente nas origens do próprio conceito de identificação partidária (Campbell et al., 1960), sua operacionalização em estudos empíricos foi relegada a segundo plano na maioria das vezes (Garry, 2007).

No clássico The civic culture, Almond e Verba (1989) já chamavam a atenção para as clivagens sociais que se manifestavam nas opções dos eleitores por esse ou aquele partido nos diferentes países que estudaram. Essas clivagens de natureza étnica e religiosa, principalmente, em grande medida eram transportadas para o sistema político com consequências positivas e negativas para a estabilidade deste.

Para esses autores os cidadãos poderiam ser divididos em quatro grupos, no que diz respeito ao seu padrão de relacionamento com os partidos. O primeiro grupo, dos "partidários abertos", reuniria pessoas emocional e cognitivamente envolvidas com o processo político eleitoral, mas que não estão envolvidas tão intensamente com uma legenda ao ponto de "[...] cut himself off from relations with members of the opposing party" (Almond e Verba, 1989, p. 114). Os "partidários apáticos" compõem o segundo grupo e podem ser caracterizados como eleitores que declaram votar em um partido específico, porém não manifestam envolvimento emocional ou cognitivo com o processo eleitoral. O terceiro grupo, dos "partidários intensos", reúne aqueles que se identificam fortemente com um dos grandes partidos e essa sua identificação faz com que a competição eleitoral com as demais legendas se converta em algo central no seu envolvimento intenso com o processo político. Por fim, teríamos os "partidários paroquiais", que apenas são identificados com um partido e preocupados com as alianças que este estabelece, mas não se envolvem racional ou emocionalmente com a competição eleitoral. O que os difere é que não votam.

Uma democracia estável seria mais comum quando a maioria do seu eleitorado apresentasse as características que marcam o primeiro desses grupos, ou seja, abertura e moderação, reduzindo assim a hostilidade entre as diferentes legendas e favorecendo a aceitação das oposições (Almond e Verba, 1989, p. 114).

Mais recentemente, Klingemann e Wattenberg (1992) avaliam mais diretamente a questão da rejeição, em termos de "gostar" ou "não gostar" de legendas partidárias, e oferecem uma nova tipologia dos eleitores. Considerando o eleitorado norte-americano e alemão, identificam primeiramente o que chamam de "eleitores antagonistas", que gostam de um partido e ativamente não gostam do partido de oposição. O segundo grupo seria composto pelos "eleitores equilibrados", capazes de identificar qualidades e defeitos nos maiores partidos do sistema. O terceiro grupo, dos "apáticos", reúne eleitores que não manifestam qualquer sentimento em relação aos principais partidos, são indiferentes a eles. Apesar de avaliarem os "equilibrados" como mais favoráveis à estabilidade, os autores estão particularmente preocupados com o movimento dos norteamericanos em direção à apatia em relação aos partidos e ao voto orientado por candidatos. Wattenberg (1998) também compartilha dessa preocupação, defendendo que os partidários antagonistas ou movidos por oposições podem eventualmente ser 
convertidos em eleitores mais tolerantes. O grande desafio estaria na incorporação daquele contingente em crescimento de pessoas não vinculadas com o processo político.

Rose e Mishler (1998), concentrando-se sobre os casos de quatro nações (Hungria, Polônia, Romênia e Eslovênia) oriundas do antigo bloco comunista no Leste Europeu, alertam para o fato de que, em países de histórico democrático recente e com baixos estoques de legitimidade democrática, a rejeição a um ou mais partidos centrais pode afetar a estabilidade do regime como um todo. Especialmente nos países analisados, que no passado contavam com um partido único, o Partido Comunista, a forte rejeição a essa legenda no novo período democrático poderia contaminar todos os demais componentes do sistema político com desconfiança e descrença. Usando dados do New Democracy Barometer (NDB), os autores identificam claramente o predomínio do que chamam de eleitores "negativos", que indicam facilmente os partidos em que não votariam, mas não são capazes de apontar uma legenda em que poderiam votar. Os eleitores "fechados", que manifestam identificação por um partido e rejeitam o partido competidor, representam apenas um quarto do eleitorado dos países analisados. Os eleitores "abertos", que, apesar de identificados com uma legenda, não são capazes de indicar em que partido não votariam, são extremamente raros entre os entrevistados. Por fim, os "apáticos" também seriam raros, em razão da forte rejeição existente. 0 quadro composto por esses autores, portanto, é bastante distinto daquele identificado nas democracias consolidadas, com inclinação à apatia. Ao menos nesses quatro países ex-comunistas, o desafio que se apresenta é gerar identificação positiva entre a maioria do eleitorado, que apenas rejeita as instituições partidárias. Como já mencionamos anteriormente, segundo Wattenberg (1998) essa tarefa é mais viável do que a reversão da apatia.

Garry (2007) buscou propor uma medida de identificação partidária para contextos multipartidários. Nesses casos, segundo o autor, seria mais apropriada uma medida de IP (Identidade Partidária) que considerasse os sentimentos negativos e positivos dos eleitores pelos partidos. Para o autor, as identidades partidárias deveriam ser tomadas como "múltiplas", "positivas" e "negativas". Tomando como base empírica a Irlanda do Norte, o autor construiu uma medida de identificação composta por essas três dimensões. Seus testes empíricos indicaram a coerência do construto e do seu forte efeito preditivo na explicação do voto. Suas conclusões indicam que em contextos multipartidários "(...) multiple identities, as well as positive and negative identities, are likely and may be key facets of the relationship between individuals and parties. Thus, wider applications of the measures offered here may yield interesting insights into voterparty relations in the multiparty setting" (Garry, 2007, p. 357).

O estudo de Medeiros e Nöel (2014) considera que as avaliações negativas dos partidos não são simplesmente o oposto bipolar da identificação partidária (positiva), como comumente foi tratado pela literatura sobre o tema. Logo, se ambas têm determinantes e consequências distintas, seria razoável abordá-las em separado. Para os 
autores, as avaliações negativas de partidos pesam na tomada de decisões. Quando elas são ativadas, por uma má experiência, por exemplo, podem produzir efeitos mais rápidos e mais fortes do que avaliações positivas ou neutras.

O estudo empírico conduzido pelos autores verificou o impacto da avaliação negativa dos partidos nas eleições nacionais da Austrália, do Canadá, da Nova Zelândia e dos Estados Unidos. Eles concluem que a IP negativa tem um impacto sobre o voto, sendo determinada principalmente pela ideologia e pela IP positiva. Indicam ainda que, mesmo nas democracias anglo-americanas, em que a oposição esquerda-direita tem sido frequentemente considerada menos relevante na explicação do comportamento político, ela acaba por influenciar a IP e o voto ${ }^{6}$.

A literatura que analisa os sentimentos negativos dos eleitores brasileiros é relativamente escassa e, com exceção do trabalho de Zucco e Samuels (2015), não trata teoricamente o tema da "identificação partidária negativa" (ou "sentimentos partidários negativos"), centrando-se mais na análise empírica. Como essa literatura ainda não parece ter sido resenhada, tentamos a seguir apresentar brevemente os trabalhos que de alguma forma mencionam esses sentimentos negativos em relação aos partidos, no Brasil, de forma a contrastar, ao final, nossas conclusões às daqueles trabalhos, bem como discutir certos aspectos metodológicos relevantes na operacionalização das variáveis envolvidas.

Salvo engano, uma primeira menção à "rejeição partidária" aparece em Almeida (1996), que, no entanto, não a relaciona com a decisão de voto dos eleitores ${ }^{7}$. Carreirão (2002) sugere a existência dessa relação embora não faça uma análise empírica ${ }^{8}$. Carreirão e Kinzo (2004), analisando um survey realizado em 1997, mostram que $41 \%$ dos eleitores manifestavam rejeição a pelo menos um partido (p. 156) ${ }^{9}$. Quanto à relação entre rejeição e voto, concluem: "a rejeição partidária parece ter um vínculo claro com o voto: em mais de $98 \%$ dos casos em que um eleitor manifestava rejeição a um partido, ele não votava no candidato deste partido" (p. 160). Carreirão e Barbetta (2004), investigando os fatores relevantes na decisão de voto na eleição presidencial de 2002, a

\footnotetext{
${ }^{6}$ Como veremos a seguir, Zucco e Samuels (2015), analisando dados sobre o PT, concluem, em oposição aos argumentos e evidências empíricas de Medeiros e Nöel: "in Brazil positive partisan identities and leftright ideology do not determine antipetismo" (Zucco e Samuels, 2015, p. 4).

7 Almeida (1996, p. 60 e p. 182) indica apenas que em dois surveys realizados em 1994 (em março pela CMPA e em setembro pelo Sensus), $44 \%$ dos eleitores manifestavam rejeição por algum partido: o partido com maior rejeição era o PT (14\% em março e $18 \%$ em setembro), seguido do PMDB (10\% e 6\%, respectivamente) e PSDB ( $1 \%$ e $3 \%$, respectivamente). Não há indicação do enunciado da pergunta sobre rejeição partidária.

8 "Mesmo sem ter preferência por um dos partidos, um eleitor pode ter rejeição por um (ou mais) deles, não votando em um candidato a ele(s) filiado (...). A escassez de dados relativos a essa rejeição aos partidos nas bases de dados disponíveis nesta pesquisa impossibilitou um teste mais sistemático dessa possível influência; julgamos, porém, que realizar uma análise deste tipo seria relevante para termos uma compreensão mais abrangente da forma como os eleitores levam os partidos em consideração ao tomar sua decisão de voto" (Carreirão, 2002, p. 116).

${ }^{9}$ Survey aplicado pela Fundação Perseu Abramo em setembro de 1997. O enunciado da pergunta era: "Desses partidos [apresentados em um cartão], qual é o partido em que você não votaria nos candidatos dele de jeito nenhum?" (resposta única).
} 
partir de um survey aplicado na região da Grande São Paulo, incluem como uma das medidas explicativas a variável "partido", buscando testar a hipótese de que "as inclinações ou os 'sentimentos' dos eleitores em face dos partidos influenciem seu voto" $\left(\right.$ p. 76) ${ }^{10}$. Carreirão (2007a), analisando os dados do Eseb 2002 referentes à eleição presidencial, inclui como preditor os "sentimentos partidários" dos eleitores, semelhante a este mencionado acima ${ }^{11}$. As análises (regressões logísticas binomiais) tanto de Carreirão e Barbetta (2004) quanto de Carreirão (2007a) mostraram que os sentimentos partidários dos eleitores afetavam significativamente o voto em Lula e Serra e, de forma menos intensa, o voto em Ciro Gomes, não afetando o voto em Garotinho.

Carreirão (2007b) analisa as manifestações positivas e negativas (rejeição) a partidos nos Esebs 2002 e 2006. Uma primeira observação ali destacada é sobre a relevância potencial do conjunto dos sentimentos partidários dos eleitores em sua decisão de voto (comparativamente à relevância de suas preferências partidárias apenas) ${ }^{12}$. O autor criou, naquele artigo, uma variável relativa aos sentimentos positivos e negativos em relação apenas ao PT e ao PSDB, na forma de uma escala em que numa extremidade (ponto 1) encontravam-se os eleitores com sentimentos positivos em relação ao PT e (simultaneamente) negativos em relação ao PSDB e, na outra extremidade (ponto 7), os eleitores com sentimentos opostos (positivos em relação ao PSDB e negativos em relação ao PT). Embora com base apenas em análise bivariada, aquele estudo mostrava uma fortíssima associação entre aquela escala de sentimentos partidários e o voto nos dois principais candidatos: a diferença pró-Lula (contra Serra) em 2002 era de $86 \%$ entre os eleitores no ponto 1 da escala, enquanto no ponto 7 da escala Serra vencia Lula por uma diferença de 66\%. Diferenças ainda maiores foram encontradas em 2006 (96\% pró-Lula e 87\% pró-Alckmin) (Carreirão, 2007b, p. 327).

Carreirão (2008), com esse mesmo tipo de operacionalização da variável, analisa dados de surveys da Fundação Perseu Abramo e do Lapop relativos às eleições presidenciais de 1998 e 2006, respectivamente, chegando a resultados bastante semelhantes àqueles. Foram feitos também cruzamentos simples entre rejeição a

\footnotetext{
${ }^{10}$ A variável "partido" (uma para cada candidato) foi construída a partir das respostas às questões sobre preferência, simpatia e rejeição partidárias. Para cada candidato a combinação dessas manifestações correspondia (dependendo dos partidos que o apoiavam) a um valor da variável "partido": " 1 , quando a combinação de preferência, simpatia e rejeição manifestadas pelo entrevistado representar, do ponto de vista teórico, uma tendência favorável ao voto no candidato em questão; 0 , quando essa combinação for neutra em relação à escolha do candidato; -1 , quando a combinação representar uma tendência negativa de voto no candidato em questão" (Carreirão e Barbetta, 2004, p. 89; ver operacionalização detalhada nas p. 89-90).

${ }^{11}$ Embora as questões do Eseb sejam um pouco diferentes das do survey para a Grande São Paulo: "For Lula and Serra, the variable included, as well as 'positive sentiments' ('party that representes you' or 'party you like'), 'negative sentiments' (rejection of the PT, in Lula's case, or rejection of the PSDB, in Serra's case)" (Carreirão, 2007a, p. 92).

12 "Os percentuais de eleitores que manifestaram algum tipo de 'sentimento partidário' - e que, portanto, potencialmente poderiam levar em consideração estes 'sentimentos' na sua decisão de voto - foram relativamente grandes: $85 \%$ (2002) e 77\% (2006). (...) As porcentagens de eleitores que manifestavam rejeição a (pelo menos) algum partido foram maiores do que aquelas de eleitores que manifestavam sentimentos positivos" (Carreirão, 2007b, p. 326).
} 
partidos e diversas opiniões políticas dos eleitores em três surveys ${ }^{13}$. Embora para a maioria das opiniões medidas não tenha havido associação significativa com a rejeição aos partidos, em alguns casos essa associação ocorria. Sem entrar aqui nos detalhes, cabe destacar a tentativa de identificar o perfil, em termos das opiniões políticas concretas, dos eleitores que manifestam rejeição a determinados partidos. Ribeiro, Carreirão e Borba (2011) analisam, para os dados do Eseb 2010 (e, em alguns casos, dos Esebs 2002 e 2006), os sentimentos partidários positivos e negativos dos eleitores, utilizando aqueles mesmos indicadores mencionados acima. Fazendo um cruzamento simples entre aquela mesma escala (de sete pontos) de sentimentos partidários e o voto para presidente (10 turno), eles mostram que novamente em 2010 a associação foi fortíssima (diferença pró-Dilma de $86 \%$ no ponto 1 da escala e diferença pró-Serra de $82 \%$ no ponto 7). Além disso, o artigo analisa associações entre sentimentos partidários e atitudes políticas dos eleitores ${ }^{14}$, a partir de modelos de regressão logística em que as atitudes eram as variáveis dependentes e os sentimentos partidários, uma das variáveis explicativas ${ }^{15}$. Embora tenham achado algumas associações, os autores destacam a "baixa capacidade explicativa para o conjunto de variáveis atitudinais". Comparando esses resultados com os da análise da relação entre sentimentos partidários e o voto, os autores concluem:

os sentimentos partidários também se mostraram associados e significativos na explicação do voto em 2010, só que em uma intensidade bem mais forte, que se refletiu na capacidade explicativa dos modelos de regressão construídos. Dessa forma, o que se depreende é que temos partidos fracos como estruturadores de atitudes (de adesão à democracia, igualitarismo, estatismo, tolerância à corrupção e aceitação da censura), mas relativamente fortes na estruturação do comportamento eleitoral (Ribeiro, Carreirão e Borba, 2011, p. 361).

Neves (2012), além de analisar a identificação partidária (positiva), testa também os efeitos da rejeição ao PT, ao PSDB e ao PMDB e identifica a sua relevância nas três eleições analisadas (2002, 2006 e 2010), tendo essa variável (no que se refere ao PT e ao PSDB), inclusive, apresentado os maiores coeficientes dos modelos.

Zucco e Samuels (2015) analisam três surveys - Fundação Perseu Abramo (FPA), 1997 e 2006, e Brazil Electoral Panel Survey (Beps), 2014 -, usando como medida de

\footnotetext{
13 Fundação Perseu Abramo (1997), Eseb (2002) e Lapop (2006).

14 Preferência pela democracia, adesão à democracia, ao estatismo, ao igualitarismo, aceitação da repressão (a manifestações populares) e aceitação da censura.

${ }_{15}$ As principais conclusões foram: "à medida que passamos dos eleitores com preferência pelo PT e rejeição ao PSDB (simultaneamente) para os eleitores com preferência pelo PSDB e rejeição ao PT (simultaneamente), diminuem a adesão à democracia, o apreço por atitudes igualitárias e por uma maior intervenção do Estado na economia. Não houve associações significativas entre esse indicador de sentimentos partidários e as variáveis atitudinais relacionadas à aceitação da repressão e da censura" (Ribeiro, Carreirão e Borba, 2011, p. 361).
} 
antipetismo qualquer resposta dos eleitores a questões desses surveys que indicasse um sentimento negativo em relação ao $\mathrm{PT}^{16}$. $\mathrm{O}$ artigo analisa inicialmente a evolução das taxas de antipetismo (total) ao longo do período (1997-2014), para depois se concentrar na análise dos "antipetistas puros", ou seja, aqueles que não gostam do PT ou não votariam nele, mas não simpatizam com nenhum outro partido. Algumas das principais conclusões daqueles autores são: i) tanto os sentimentos pró-PT quanto os anti-PT influenciam fortemente as decisões de voto de parcela significativa do eleitorado; ii) quanto às fontes socioeconômicas e atitudinais do antipetismo: antipetistas não são conservadores; tendem a ser relativamente ricos, mas acreditam que o PT administrou mal a economia; manifestam sentimentos anticorrupção (desde 2006), porém mais importante são as atitudes negativas contra políticas de ação afirmativa que beneficiam afro-brasileiros ${ }^{17}$.

Com essa breve revisão, nossa intenção foi destacar a atenção ainda incipiente que o tema da identificação partidária negativa tem recebido, especialmente se comparada ao volume expressivo de pesquisas sobre a dimensão positiva desse fenômeno. Ainda assim, a literatura tem apontado para a sua relevância, especialmente em contextos de democratização recente. No cenário nacional, em que as pesquisas sobre esse assunto são ainda mais escassas, os estudos apontam para a sua relevância em termos eleitorais.

\section{Sentimentos partidários no Brasil (2002-2014)}

Nesta seção descrevemos a distribuição dos eleitores segundo os sentimentos partidários que manifestaram nos Esebs 2002, 2006, 2010 e 2014. Cabe inicialmente uma consideração de ordem metodológica: em artigo anterior (Ribeiro, Carreirão e Borba, 2011) havíamos considerado como manifestações de sentimentos positivos em relação aos partidos as respostas às questões: "Existe algum partido que representa a forma como o(a) sr(a). pensa?" (espontânea e única) e "Existe algum partido que o(a) $\operatorname{sr}(a)$. goste?" (espontânea e múltipla, podendo o eleitor mencionar até três opções). E, como manifestação negativa, as respostas à questão sobre rejeição partidária ("Em quais desses partidos o(a) sr(a). não votaria de jeito nenhum?", estimulada e múltipla). No Eseb 2014, porém, a primeira e a última das questões acima não foram aplicadas, como haviam sido nos estudos anteriores. Como nosso pressuposto é o de que os sentimentos negativos em relação aos partidos são relevantes e estão relacionados tanto com

\footnotetext{
${ }^{16}$ Nos surveys da FPA havia duas questões: uma perguntava sobre o partido que o eleitor não gostava (podendo o respondente indicar até oito partidos); a outra é a tradicional pergunta de rejeição (sobre o partido que o entrevistado não votaria). No survey de 2006, cada questão foi aplicada a uma metade da amostra. A pergunta feita no Beps era sobre o partido que o eleitor não gostava (resposta única) (Zucco e Samuels, 2015, p. 5-6).

${ }_{17}$ Cabe assinalar que essas conclusões referem-se aos "antipetistas puros" e não necessariamente aos demais antipetistas (que manifestam sentimentos positivos em relação a outros partidos), já que estes não foram objeto daquela análise.
} 
atitudes políticas quanto com a decisão de voto dos eleitores, a única maneira de realizar uma análise incluindo simultaneamente os sentimentos positivos e negativos dos eleitores em relação aos partidos é utilizando as respostas a uma questão que solicitava aos entrevistados que atribuíssem uma nota (de 0 a 10) a 12 partidos (incluindo os mais relevantes do atual sistema partidário) ${ }^{18}$. Assim, embora não tenha sido possível comparar rigorosamente os resultados da presente análise com os da análise anterior, mencionada acima, é possível pelo menos descrever a evolução dos sentimentos partidários positivos e negativos dos eleitores em relação aos partidos, já que essa mesma questão foi aplicada em todos os Esebs.

Mesmo que não tenha sido aplicada a questão relativa ao "partido que representa a forma como o(a) sr(a). pensa", de todo modo, inicialmente apresentamos os dados relativos aos sentimentos positivos em relação a alguns dos principais partidos brasileiros, tal como havíamos operacionalizado no trabalho anterior (Ribeiro, Carreirão e Borba, 2011). A seguir descrevemos as notas atribuídas a PT e PSDB, partidos em relação aos quais desenvolveremos nossa análise. Por fim, criamos uma variável que sintetiza o conjunto de sentimentos (positivos e negativos) em relação ao PT e ao PSDB simultaneamente.

A Tabela 1 mostra a evolução dos sentimentos positivos em relação a alguns dos principais partidos brasileiros entre 2002 e 2014. Quanto ao partido que "melhor representa a maneira como o eleitor pensa", percebe-se que entre 2002 e 2010 o DEM (PFL) e o PMDB declinaram continuamente, enquanto o PV cresceu (o que parece estar associado à candidatura de Marina em 2010), sendo essa também a tendência mais geral do PSDB. No caso do PT, houve um declínio em 2006, por conta das denúncias relacionadas ao "Mensalão", com o partido voltando, em 2010, a um patamar até levemente superior a 2002.

\footnotetext{
18 "Gostaria de saber com mais detalhes o que o(a) sr(a). pensa sobre alguns partidos políticos. Por favor, para cada partido que eu citar, gostaria que atribuísse uma nota de 0 a 10 , sendo que 0 significa que o(a) $\operatorname{sr}(a)$. não gosta de jeito nenhum do partido e 10 que o(a) $\operatorname{sr}(a)$. gosta muito. Se eu falar o nome de um partido que o(a) sr(a). não conhece, apenas diga que não o conhece".
} 
Tabela 1

Partidos que melhor representam a maneira como o eleitor pensa e partidos de que o eleitor gosta (2002-2014) (\%)

\begin{tabular}{|c|c|c|c|c|c|c|c|c|c|c|c|c|}
\hline \multirow{2}{*}{ Ano } & \multicolumn{2}{|c|}{ DEM(PFL) } & \multicolumn{2}{c|}{ PMDB } & \multicolumn{2}{c|}{ PT } & \multicolumn{2}{c|}{ PSDB } & \multicolumn{2}{c|}{ PV } & \multicolumn{2}{c|}{ TOTAL } \\
\cline { 2 - 15 } & Pensa & Gosta & Pensa & Gosta & Pensa & Gosta & Pensa & Gosta & Pensa & Gosta & Pensa & Gosta \\
\hline 2002 & 2,2 & 3,4 & 3,8 & 7,2 & 23,1 & 25,6 & 3,7 & 4,5 & 0,2 & 0,6 & 35,5 & 48,8 \\
\hline 2006 & 0,5 & 0,7 & 3,7 & 3,4 & 17,6 & 21,6 & 3,6 & 4,5 & 0,4 & 0,6 & 27,4 & 33,1 \\
\hline 2010 & 0,5 & 0,8 & 2,7 & 5,2 & 24,5 & 27,7 & 5,7 & 7,8 & 3,7 & 3,5 & 38,7 & 47,7 \\
\hline 2014 & - & 0,5 & - & 3,2 & - & 18 & - & 6,6 & - & 0,8 & - & 26,2 \\
\hline
\end{tabular}

Fonte: Esebs (de 2002 a 2014).

Notas: a) para o ano de 2014 a pergunta sobre qual partido representa o pensamento do eleitor não foi aplicada; b) os percentuais para cada partido levam em consideração os que responderam que não gostam ou não têm nenhum partido como representante do seu pensamento; c) no caso da pergunta sobre qual o partido que melhor representa o que o eleitor pensa, os valores da coluna total não são iguais à soma dos percentuais por partido, porque há outros partidos mencionados pelos eleitores que não aparecem na tabela. No caso da pergunta relativa a qual o partido que o eleitor gosta, além disso, como a resposta era múltipla, a soma dos percentuais de cada partido pode ser maior do que o "total", que representa o percentual de eleitores que indicaram um ou mais partidos.

Quanto à manifestação em relação ao "partido que mais gosta", no caso do PT a tendência é igual à do indicador anterior; além disso, em 2014 a queda foi ainda maior do que a ocorrida em 2006, tendo o partido atingido agora seu pior desempenho junto ao eleitorado, tomando as pesquisas do Eseb como referência. As denúncias de corrupção no âmbito da operação "Lava Jato" (ou do chamado "Petrolão") parecem ter tido boa parte da responsabilidade por essa última queda. O PV, por não contar dessa vez com um(a) candidato(a) forte, retomou seus patamares pré-2010, o que mostra que em períodos eleitorais há certo grau de contaminação dos sentimentos partidários, conforme os candidatos lançados pelos partidos especialmente na disputa presidencial. O DEM mantém em 2014 sua trajetória de declínio; PMDB e PSDB, que haviam aumentado o percentual de eleitores que diziam gostar desses partidos em 2010, declinaram em 2014. $\mathrm{Na}$ realidade, houve um declínio geral das manifestações positivas em relação ao conjunto de partidos em 2014: se em 2010 eram 48\% os eleitores que diziam gostar de algum partido, esse percentual declina para $26 \%$ em 2014 - uma queda brutal que revela o descontentamento dos eleitores com o sistema partidário nesse período recente.

$\mathrm{Na}$ Tabela 2 vemos as notas atribuídas àqueles que têm se mostrado os dois principais partidos nas eleições presidenciais desde 1994. Essas notas são obtidas pela seguinte pergunta: Agora gostaria de saber com mais detalhes o que o(a) sr(a). pensa sobre alguns partidos políticos. Por favor, para cada partido que eu citar, gostaria que atribuísse uma nota de 0 a 10, sendo que 0 significa que $o(a) \operatorname{sr}(a$.$) não gosta de jeito$ nenhum do partido e 10 que o(a) sr(a). gosta muito. Se eu falar o nome de um partido que $o$ (a) $\operatorname{sr}(a$.) não conhece, apenas diga que não o conhece. É esse indicador que será utilizado para operacionalizar boa parte das análises feitas neste artigo. Consideramos 
como manifestação de "sentimentos negativos" em relação aos partidos as notas de 0 a 3, enquanto notas de 7 a 10 foram consideradas como manifestação de "sentimentos positivos". Notas de 4 a 6 foram consideradas avaliações "neutras" em relação a um partido.

Tabela 2

Porcentagens de eleitores, segundo notas atribuídas a PT e PSDB separadamente $(2002-2014)(\%)$

\begin{tabular}{|c|c|c|c|c|c|c|}
\hline \multirow{2}{*}{ Ano } & \multicolumn{3}{|c|}{ PT } & \multicolumn{3}{c|}{ PSDB } \\
\cline { 2 - 7 } & $\mathbf{0 - 3}$ & $\mathbf{4 - 6}$ & $\mathbf{7 - 1 0}$ & $\mathbf{0 - 3}$ & $\mathbf{4 - 6}$ & $\mathbf{7 - 1 0}$ \\
\hline 2002 & 27,9 & 20,1 & 52 & 43,6 & 31,6 & 24,9 \\
\hline 2006 & 37,1 & 28,4 & 34,5 & 46,2 & 39,6 & 14,3 \\
\hline 2010 & 26,7 & 26,4 & 46,9 & 41,5 & 32,6 & 26 \\
\hline 2014 & 37,3 & 22,6 & 40,1 & 42,3 & 29,6 & 28,1 \\
\hline
\end{tabular}

Fonte: Esebs (de 2002 a 2014).

No caso do PT, as tendências são claras: aumento das avaliações negativas e diminuição das positivas em 2006 ("Mensalão") e em 2014 ("Petrolão"/"Lava Jato"), comparativamente às eleições anteriores (2002 e 2010, respectivamente). Quanto ao PSDB, 2006 foi seu pior momento (maior percentual de avaliações negativas e menor percentual de avaliações positivas). Na realidade os percentuais de eleitores que avaliam mal o partido sempre foram elevados (entre $42 \%$ e $46 \%$ ) e maiores do que os percentuais de eleitores que avaliam mal o PT (mesmo em 2006 e 2014). Já em relação às avaliações positivas sobre o PSDB, o percentual de eleitores praticamente dobrou entre 2006 e 2014. De toda forma, também nesse quesito o desempenho do PT foi melhor em cada um dos anos analisados. Assim, tomando como indicador dos sentimentos partidários as notas atribuídas pelos eleitores aos partidos, mesmo em seus piores momentos o PT tem estado numa situação melhor do que seu principal adversário. Ao final do artigo faremos uma observação de natureza metodológica quanto a isso.

Na Tabela 3 criamos uma variável que sintetiza o conjunto de sentimentos (positivos e negativos) em relação ao PT e ao PSDB simultaneamente ${ }^{19}$. Foram consideradas como "avaliação negativa" de um partido notas de 0 a 3; "avaliação neutra" notas de 4 a 6 e "avaliação positiva" notas de 7 a 10. Nas colunas de avaliação "positiva PT" e "negativa PT", as avaliações relativas ao PSDB foram neutras. Inversamente, nas colunas de avaliação "positiva PSDB" e "negativa PSDB", as avaliações relativas ao PT

\footnotetext{
19 Variável semelhante à que já havia sido criada em estudos anteriores, conforme já mencionado na seção anterior, "Identificação partidária" (Carreirão, 2007b, 2008; Ribeiro, Carreirão e Borba, 2011); a diferença é que naqueles estudos a base eram as questões sobre sentimentos partidários positivos e negativos mencionadas anteriormente; aqui, a base foi a questão sobre avaliação (notas de 0 a 10) dos partidos (ver detalhamento a seguir).
} 
foram neutras. Foram consideradas "situações neutras" aquelas em que o eleitor manifestou a mesma avaliação (positiva, neutra ou negativa) em relação aos dois partidos simultaneamente. Foram desconsiderados na análise os entrevistados cuja resposta foi "não sabe" ou "não respondeu" à pergunta sobre avaliação dos partidos. Como o sistema partidário brasileiro é provavelmente o mais fragmentado do mundo em termos de representação na Câmara baixa e considerando que os eleitores manifestam sentimentos positivos e/ou negativos em relação a diferentes partidos, captar a influência de todos esses sentimentos sobre a decisão de voto não é tarefa fácil. A variável em questão foi criada para tentar captar, de forma simplificada, parte significativa dessa influência, pelo menos nas eleições presidenciais, que têm sido polarizadas pelos dois partidos há pelo menos 20 anos.

Tabela 3

Porcentagens de eleitores em cada categoria de avaliação em relação a PT e PSDB simultaneamente (2002-2014) (\%)

\begin{tabular}{|c|c|c|c|c|c|c|c|}
\hline Ano & $\begin{array}{c}\text { Positiva PT } \\
\text { e negativa } \\
\text { PSDB }\end{array}$ & $\begin{array}{c}\text { Positiva } \\
\text { PT }\end{array}$ & $\begin{array}{c}\text { Negativa } \\
\text { PSDB }\end{array}$ & $\begin{array}{c}\text { Situações } \\
\text { neutras }\end{array}$ & $\begin{array}{c}\text { Negativa } \\
\text { PT }\end{array}$ & $\begin{array}{c}\text { Positiva } \\
\text { PSDB }\end{array}$ & $\begin{array}{c}\text { Positiva PSDB } \\
\text { e negativa PT }\end{array}$ \\
\hline 2002 & 23 & 17 & 8 & 30 & 7 & 5 & 9 \\
\hline 2006 & 15 & 14 & 9 & 44 & 10 & 3 & 6 \\
\hline 2010 & 21 & 14 & 9 & 34 & 6 & 6 & 10 \\
\hline 2014 & 15 & 12 & 7 & 40 & 7 & 5 & 13 \\
\hline
\end{tabular}

Fonte: Esebs (de 2002 a 2014).

Inicialmente cabe destacar que, nesses quatro anos eleitorais, se levarmos em conta apenas o confronto entre os candidatos desses dois partidos (desconsiderando os demais candidatos), temos entre $57 \%$ e $69 \%$ dos eleitores que manifestam sentimentos partidários que, pelo menos teoricamente, poderiam afetar seu voto em favor de um dos dois candidatos $^{20}$. Assim, na forma como consideramos aqui o conjunto de sentimentos em relação aos dois partidos, o eleitorado que potencialmente leva em consideração os partidos ao decidir seu voto é significativo e bem superior àquele encontrado quando consideramos apenas os eleitores que manifestam algum tipo de sentimento partidário positivo por esses partidos ${ }^{21}$.

\footnotetext{
${ }^{20}$ Somando, para cada ano, os percentuais de todas as colunas exceto a coluna "situações neutras", temos 69\% (em 2002), 57\% (2006), 66\% (2010) e 59\% (2014). Estes são os percentuais de eleitores em cada ano cujos sentimentos partidários julgamos que poderiam potencialmente afetar seu voto na disputa presidencial entre PT e PSDB. Utilizando as variáveis relativas a sentimentos positivos e negativos tais como as tínhamos operacionalizado anteriormente (Ribeiro, Carreirão e Borba, 2011, p. 342), havíamos chegado a percentuais de "situações neutras" de 39\% (2002), 45\% (2006) e 39\% (2010), valores um pouco maiores do que os que encontramos aqui para essas três eleições.

${ }^{21}$ Consideramos que eleitores que são "neutros" em relação ao PT, mas avaliam negativamente o PSDB, encontram-se numa situação mais favorável a votar no candidato do PT do que no do PSDB; inversamente, consideramos que eleitores que são "neutros" em relação ao PSDB, mas avaliam negativamente o PT, 
Como essa variável é uma combinação das notas de PT e PSDB apresentadas na Tabela 2, as tendências só podem ser semelhantes às mencionadas na análise daquela tabela. Em todos os anos a situação tem sido melhor para os candidatos do PT do que para os candidatos do PSDB. E isso foi ainda mais claro em 2002 e 2010, em que os percentuais de eleitores em situações pró-candidato do PT superaram em muito os percentuais de eleitores em situações pró-candidato do PSDB. Em 2002, em alguma situação das três primeiras colunas (situações pró-candidato do PT) estavam 48\% dos eleitores, contra apenas $21 \%$ nas três últimas colunas (situações pró-candidato do PSDB). Em 2010 esses percentuais eram de 44\% e 22\%, respectivamente. Em 2014 a vantagem pró-candidato do PT foi a menor da série: $34 \%$ dos eleitores em situações prócandidato do PT, contra $25 \%$ em situações pró-candidato do PSDB. Além disso, os percentuais das posições mais extremas da Tabela 3 se aproximaram bastante: 15\% dos eleitores manifestaram avaliação positiva do PT e negativa do PSDB, contra $13 \%$ em situação inversa: avaliação positiva do PSDB e negativa do PT. Isso é relevante porque teoricamente é nesses contingentes de eleitores que se pode esperar que os sentimentos partidários tenham maior influência na decisão de voto, em disputas que têm sido sempre polarizadas pelos dois partidos.

\section{Antipetismo}

Especialmente de 2014 para cá, além do declínio das manifestações de preferência, têm crescido as manifestações de rejeição ao PT, especialmente por conta das denúncias de corrupção envolvendo o partido ${ }^{22}$. Esse é um fenômeno que pode ter impactos significativos no processo eleitoral e no sistema partidário brasileiro em curto e médio prazo, merecendo, portanto, uma análise mais sistemática.

Nesta seção, descrevemos inicialmente a evolução dos percentuais de eleitores "antipetistas" entre 2002 e 2014, tomando como indicador de antipetismo as avaliações negativas (notas de 0 a 3 ) feitas pelos eleitores em relação ao PT. Além disso, diferenciamos, no interior desse grupo, três subgrupos de eleitores, conforme sua avaliação em relação ao PSDB (positiva, neutra ou negativa). Para cada um desses três grupos de antipetistas, vamos verificar qual seu perfil sociodemográfico e quais suas atitudes em relação à democracia, ao igualitarismo e ao estatismo.

Na última coluna da Tabela 4 vemos que o comportamento da variável sugere um padrão que acompanha os grandes escândalos de corrupção envolvendo a legenda

encontram-se numa situação mais favorável a votar no candidato do PSDB do que no candidato do PT. Dessa forma, as três primeiras colunas da Tabela 3 são consideradas aqui como referentes a sentimentos partidários que favorecem candidatos do PT, enquanto as três últimas são referentes a sentimentos que favorecem candidatos do PSDB.

22 Note-se que a rejeição ao PT não cresceu muito em 2006 (17\%) comparativamente a 2002 (16\%), tomando como referência as respostas à pergunta clássica sobre rejeição ("em que partido você não votaria de jeito nenhum") nos Esebs (Ribeiro, Carreirão e Borba, 2011). Para dados mais recentes, ver o trabalho de Zucco e Samuels (2015). 
("Mensalão" e "Petrolão"), já que começa em 28\% em 2002, sofre elevação para 39\% em 2006, retorna para 28 pontos em 2010 e volta a subir para $40 \%$ em $2014^{23}$.

Tabela 4

Evolução de três subgrupos de antipetistas (2002-2014) (\% de respondentes em cada categoria)

\begin{tabular}{|c|c|c|c|c|}
\hline Ano & $\begin{array}{c}\text { Negativo PT } \\
\text { e positivo PSDB }\end{array}$ & $\begin{array}{c}\text { Negativo PT } \\
\text { e neutro PSDB }\end{array}$ & $\begin{array}{c}\text { Negativo PT } \\
\text { e negativo PSDB }\end{array}$ & $\begin{array}{c}\text { Total negativo } \\
\text { PT }\end{array}$ \\
\hline 2002 & 9 & 7 & 12 & 28 \\
\hline 2006 & 6 & 10 & 23 & 39 \\
\hline 2010 & 10 & 6 & 12 & 28 \\
\hline 2014 & 13 & 7 & 20 & 40 \\
\hline
\end{tabular}

Fonte: Esebs (de 2002 a 2014).

Nota: Foram consideradas como "avaliação negativa" de um partido, notas de 0 a 3; "avaliação neutra" notas de 4 a 6; e "avaliações positivas" notas de 7 a 10. Foram desconsiderados na análise os entrevistados cuja resposta foi "não sabe" ou "não conhece" à pergunta sobre avaliação dos partidos.

Em todos os anos, o percentual maior de antipetistas é do subgrupo que avalia mal também o PSDB. E é nesse subgrupo que a evolução ao longo do tempo é semelhante à do grupo de antipetistas como um todo.

Procurando traçar um perfil sociodemográfico do eleitor que manifesta o antipetismo, conduzimos para cada um dos anos modelos de regressão logística tomando essa variável indicadora como resposta.

$\mathrm{Na}$ Tabela 5 a variável de antipetismo foi assim operacionalizada: recodificamos as notas de 0 a 3 como 1 e as demais como 0 (ou seja, os "não antipetistas" - aqueles que não avaliam mal o PT - são tomados como categoria de referência).

\footnotetext{
${ }^{23}$ Os percentuais da coluna "Total negativo PT" diferem um pouco dos indicados na coluna "PT (0-3)" da Tabela 2, porque o denominador sobre o qual foram calculados é diferente. O número de casos válidos é menor na Tabela 4 (onde o número de missing cases é maior, pelo fato de que, ao cruzarmos as duas variáveis - notas dadas ao PT e ao PSDB -, esse número tende a ser maior do que quando considerada uma das variáveis somente).
} 
Tabela 5

Perfil sociodemográfico dos antipetistas (regressões logísticas) - 2002-2014

\begin{tabular}{|c|c|c|c|c|}
\hline Variável & 2002 & 2006 & 2010 & 2014 \\
\hline Sexo & $\begin{array}{l}1,014 \\
(, 095)\end{array}$ & $\begin{array}{c}799 \\
(, 136)\end{array}$ & $\begin{array}{c}896 \\
(, 105)\end{array}$ & $\begin{array}{l}1,005 \\
(, 092)\end{array}$ \\
\hline Faixa etária & $\begin{array}{c}1,172 * * \\
(, 038)\end{array}$ & $\begin{array}{l}1,043 \\
(, 056)\end{array}$ & $\begin{array}{l}1,073 \\
(, 039)\end{array}$ & $\begin{array}{l}1,029 \\
(, 032)\end{array}$ \\
\hline Escolaridade & $\begin{array}{l}1,100 \\
(, 066)\end{array}$ & $\begin{array}{c}1,136 * * \\
(, 035)\end{array}$ & $\begin{array}{c}1,065^{*} \\
(, 025)\end{array}$ & $\begin{array}{c}1,157^{* *} \\
(, 023)\end{array}$ \\
\hline Grupo étnico (branco) & $\begin{array}{l}1,327^{*} \\
(, 098)\end{array}$ & - & $\begin{array}{c}1,638 * * \\
(, 106)\end{array}$ & $\begin{array}{c}1,343^{*} \\
(, 095)\end{array}$ \\
\hline Residência (capital) & $\begin{array}{l}1,186 \\
(, 102) \\
\end{array}$ & - & - & - \\
\hline Interesse por política & $\begin{array}{c}672 * * \\
(, 078)\end{array}$ & - & - & $\begin{array}{c}816 * * \\
(, 053) \\
\end{array}$ \\
\hline
\end{tabular}

Fonte: Esebs (de 2002 a 2014).

Nota: Os valores correspondem aos $\operatorname{Exp}(B)$ e entre parênteses são apresentados os erros padronizados $*$ Sig. $=0,000 . * *$ Sig. $\leq 0,05$.

A idade foi uma variável relevante apenas em 2002: o antipetismo aumentava com a idade dos eleitores. Em 2006, 2010 e 2014, quanto maior a escolaridade dos eleitores, maior a chance de serem antipetistas. Em 2002, 2010 e 2014, a probabilidade de ser antipetista era maior entre os eleitores brancos do que entre os não brancos. 0 antipetismo diminuía entre os eleitores mais interessados na política, em 2002 e 2014.

Como julgamos que poderia haver diferenças entre os perfis dos eleitores de cada um dos subgrupos de antipetistas, na Tabela 6 novamente os "não antipetistas" são a referência, mas dessa vez em modelo multinomial com quatro categorias para 2014.

Os resultados do modelo indicam que, à medida que aumenta a faixa etária dos eleitores, aumenta a chance de serem eleitores antipetistas que avaliam positivamente ou de forma neutra o PSDB (comparativamente a serem eleitores não antipetistas). Mas diminui a chance de serem eleitores antipetistas que também são antipessedebistas. A escolaridade está associada positivamente a todos os subgrupos de antipetistas. Brancos são mais significativamente antipetistas (do que outras etnias) apenas na categoria de antipetistas que avaliam positivamente o PSDB. Interesse pela política se associa positivamente com o antipetismo que avalia positivamente o PSDB, mas negativamente com as outras duas categorias de antipetistas. Assim, pode-se dizer que antipetistas próPSDB são brancos, mais velhos, mais escolarizados e com maior interesse pela política do que os não antipetistas; além disso, entre os brancos é maior a chance de um eleitor ter esse perfil de antipetismo (pró-PSDB) do que ter um perfil de não antipetista. Antipetistas que são simultaneamente antipessedebistas tendem a ser mais jovens e com menor interesse pela política, mas mais escolarizados do que os não antipetistas. Antipetistas que são neutros em relação ao PSDB são mais velhos, mais escolarizados, mas com menor interesse pela política do que os não antipetistas. O perfil dos antipetistas que avaliam bem o PSDB é mais claro (comparativamente ao perfil dos não 
antipetistas): pessoas brancas, mais velhas, de alta escolaridade e interessadas em política. Para os outros dois grupos, escolaridade e interesse pela política vão em direções opostas.

Tabela 6

Perfil sociodemográfico dos subgrupos antipetistas (regressões logísticas) - 2014

\begin{tabular}{|c|c|c|c|}
\hline & \multicolumn{3}{|c|}{2014} \\
\hline & $\begin{array}{c}-\mathrm{PT} / \\
\text {-PSDB }\end{array}$ & $\begin{array}{c}-\mathrm{PT} / \\
\varnothing \mathrm{PSDB} \\
\end{array}$ & $\begin{array}{c}-\mathrm{PT} / \\
+\mathrm{PSDB}\end{array}$ \\
\hline Sexo & $\begin{array}{l}1,015 \\
(, 123) \\
\end{array}$ & $\begin{array}{c}, 910 \\
(, 185) \\
\end{array}$ & $\begin{array}{c}919 \\
(, 145) \\
\end{array}$ \\
\hline Faixa etária & $\begin{array}{l}\prime 919 * \\
(, 044)\end{array}$ & $\begin{array}{l}\left(, 150^{*}\right. \\
(, 064)\end{array}$ & $\begin{array}{l}1,119 * \\
(, 050)\end{array}$ \\
\hline Escolaridade & $\begin{array}{l}1,092^{*} \\
(, 032) \\
\end{array}$ & $\begin{array}{l}1,172^{*} \\
(, 046) \\
\end{array}$ & $\begin{array}{c}1,170 * * \\
(, 036)\end{array}$ \\
\hline Grupo étnico (branco) & $\begin{array}{l}1,067 \\
(129) \\
\end{array}$ & $\begin{array}{l}1,347 \\
(, 187) \\
\end{array}$ & $\begin{array}{c}1,984 * * \\
(, 145)\end{array}$ \\
\hline Interesse por política & $\begin{array}{l}581^{* *} \\
(, 076)\end{array}$ & $\begin{array}{l}, 768^{*} \\
(108)\end{array}$ & $\begin{array}{c}1,234^{*} \\
(, 080)\end{array}$ \\
\hline $\begin{array}{l}\text { Cox e Snell } \\
\text { Nagelkerke }\end{array}$ & \multicolumn{3}{|c|}{$\begin{array}{l}080 \\
090\end{array}$} \\
\hline
\end{tabular}

Fonte: Esebs (de 2002 a 2014).

Nota: $\varnothing=$ "neutro" (avaliação entre 4 e 6 ).

Categoria de referência $=$ não antipetistas.

$*$ Sig. $=0,000 ; * *$ sig. $\leq 0,05$.

Além de tentar compreender o perfil sociodemográfico dos diferentes subgrupos de eleitores antipetistas, interessa-nos também analisar suas atitudes políticas. Serão estudadas a preferência pela democracia, a adesão a ela, bem como as atitudes dos eleitores antipetistas perante o Estado (estatismo) e a igualdade (igualitarismo).

Nessa etapa da análise nos limitamos ao ano de 2014 e, assim como procedemos antes, para cada variável atitudinal iniciamos com um modelo de regressão logística tomando como principal variável dependente uma medida dicotômica que contrasta os antipetistas com aqueles eleitores que não avaliam mal o PT. A seguir, desagregamos mais a análise, contrastando os não antipetistas com cada um dos três subgrupos de antipetistas. Como optamos por apresentar conjuntamente os resultados de todos esses modelos, para cada atitude temos duas colunas, uma contendo apenas o contraste dicotômico (modelo logístico binário) e outra com as quatro categorias (modelo logístico multinomial).

No que diz respeito à "adesão à democracia" ${ }^{24}$, vemos (Tabela 7) que as variáveis relativas às disposições partidárias dos eleitores não se mostraram relevantes

\footnotetext{
24 "Adesão à democracia" é uma questão já clássica nos estudos sobre valores políticos e foi baseada na questão: "A democracia tem alguns problemas, mas é melhor do que qualquer outra forma de governo. $\mathrm{O}(\mathrm{a}) \operatorname{sr}(\mathrm{a})$. concorda ou discorda dessa afirmação? Muito ou pouco? 1) Concorda muito; 2) Concorda um pouco; 3) Nem concorda nem discorda; 4) Discorda um pouco; 5) Discorda muito". Recodificamos a 
em ambos os modelos. Não parece existir diferença, portanto, entre antipetistas e eleitores que não apresentam sentimentos negativos por essa legenda, mas também entre os diferentes tipos de antipetistas e o grupo de controle. As duas únicas variáveis que apresentaram efeitos significativos foram a idade e o interesse por política, nos dois modelos, porém com sentidos inversos. Enquanto a idade reduz a chance de adesão, o interesse aparece como um consistente impulsionador.

Confirmando a consistência desses resultados, cenário bastante semelhante é verificado no que diz respeito à "preferência pela democracia" ${ }^{25}$. As variáveis relativas aos partidos continuam apresentando efeito estatisticamente irrelevante, enquanto o interesse por política se consolida como um bom preditor. Diferentemente do que ocorreu nos modelos anteriores, a idade agora deixa de ser relevante. Em síntese, considerando essas duas medidas clássicas de adesão à democracia, podemos concluir que o antipetismo não guarda relação direta com disposições subjetivas contrárias ou favoráveis a elas, ao menos considerando essa dimensão mais abstrata do apoio, na forma como desenvolvida por Easton (1963).

\section{Tabela 7 \\ Regressões logísticas binárias e multinomiais para atitudes políticas (2014)}

\begin{tabular}{|c|c|c|c|c|c|c|c|c|}
\hline & \multicolumn{2}{|c|}{$\begin{array}{c}\text { Adesão à } \\
\text { democracia }\end{array}$} & \multicolumn{2}{|c|}{$\begin{array}{c}\text { Preferência pela } \\
\text { democracia }\end{array}$} & \multicolumn{2}{|c|}{ Igualitarismo } & \multicolumn{2}{|c|}{ Estatismo } \\
\hline & Anti-PT & Grupos & Anti-PT & Grupos & Anti-PT & Grupos & Anti-PT & Grupos \\
\hline Sexo & $\begin{array}{l}1,069 \\
(, 101) \\
\end{array}$ & $\begin{array}{l}1,113 \\
(, 108) \\
\end{array}$ & $\begin{array}{l}, 970 \\
(, 117) \\
\end{array}$ & $\begin{array}{l}1,003 \\
(, 123) \\
\end{array}$ & $\begin{array}{c}, 894 \\
(, 096) \\
\end{array}$ & $\begin{array}{l}, 874 \\
(, 101) \\
\end{array}$ & $\begin{array}{l}997 \\
(, 106) \\
\end{array}$ & $\begin{array}{l}, 974 \\
(, 112) \\
\end{array}$ \\
\hline Faixa etária & $\begin{array}{l}931^{*} \\
(, 035) \\
\end{array}$ & $\begin{array}{l}, 928^{*} \\
(, 038) \\
\end{array}$ & $\begin{array}{l}941 \\
(, 041) \\
\end{array}$ & $\begin{array}{l}1932 \\
(, 043)\end{array}$ & $\begin{array}{l}936^{*} \\
(, 034) \\
\end{array}$ & $\begin{array}{l}1952 \\
(, 036) \\
\end{array}$ & $\begin{array}{c}9999 \\
(, 037) \\
\end{array}$ & $\begin{array}{l}, 988 \\
(, 039) \\
\end{array}$ \\
\hline Escolaridade & $\begin{array}{l}1,016 \\
(, 025) \\
\end{array}$ & $\begin{array}{l}1,032 \\
(, 027) \\
\end{array}$ & $\begin{array}{l}1,023 \\
(, 029) \\
\end{array}$ & $\begin{array}{l}1,035 \\
(, 031)\end{array}$ & $\begin{array}{c}958 \\
(, 024) \\
\end{array}$ & $\begin{array}{l}976 \\
(, 026)\end{array}$ & $\begin{array}{l}968 \\
(, 026)\end{array}$ & $\begin{array}{l}1964 \\
(, 028)\end{array}$ \\
\hline $\begin{array}{l}\text { Grupo étnico } \\
\text { (branco) }\end{array}$ & $\begin{array}{l}, 991 \\
(, 105)\end{array}$ & $\begin{array}{l}1,044 \\
(, 112)\end{array}$ & $\begin{array}{c}, 901 \\
(, 121) \\
\end{array}$ & $\begin{array}{l}, 981 \\
(, 128)\end{array}$ & $\begin{array}{l}\text {,716* } \\
(, 101) \\
\end{array}$ & $\begin{array}{l}, 731^{*} \\
(, 106) \\
\end{array}$ & $\begin{array}{l}1,017 \\
(, 110)\end{array}$ & $\begin{array}{l}1,002 \\
(, 116)\end{array}$ \\
\hline $\begin{array}{l}\text { Interesse por } \\
\text { política }\end{array}$ & $\begin{array}{l}1,145^{*} \\
(, 059) \\
\end{array}$ & $\begin{array}{l}1,145^{*} \\
(, 063) \\
\end{array}$ & $\begin{array}{l}1,196 * \\
(, 068) \\
\end{array}$ & $\begin{array}{l}1,206^{*} \\
(, 072)\end{array}$ & $\begin{array}{l}, 958 \\
(, 055) \\
\end{array}$ & $\begin{array}{l}, 977 \\
(, 059) \\
\end{array}$ & $\begin{array}{l}1,062 \\
(, 060) \\
\end{array}$ & $\begin{array}{l}1,026 \\
(, 064)\end{array}$ \\
\hline Antipetismo & $\begin{array}{l}, 937 \\
(105) \\
\end{array}$ & - & $\begin{array}{l}1796 \\
(, 120) \\
\end{array}$ & - & $\begin{array}{c}, 829 \\
(, 100) \\
\end{array}$ & - & $\begin{array}{l}876 \\
(, 111) \\
\end{array}$ & - \\
\hline Não antipetista & _- & $a$ & _- & $a$ & - & $a$ & - & $a$ \\
\hline
\end{tabular}

variável como dicotômica, juntando os valores 3 (nem concorda, nem discorda), 4 (discorda um pouco) e 5 (discorda muito) no novo valor 0 e juntando 1 (concorda um pouco) e 2 (concorda muito) no novo valor 1 ". 25 Também uma variável usual nos estudos de cultura política, "preferência pela democracia", foi construída a partir da questão: "Na sua opinião: 1 - A democracia é sempre melhor que qualquer outra forma de governo; ou 2 - Em algumas situações é melhor uma ditadura do que uma democracia; 3 - Tanto faz/nenhuma das duas é melhor (espontânea)". Operacionalizamos a medida como uma variável dicotômica, juntando as respostas 2 e 3 (que assumem o valor 0 na nova variável). 


\begin{tabular}{|c|c|c|c|c|c|c|c|c|}
\hline & \multicolumn{2}{|c|}{$\begin{array}{c}\text { Adesão à } \\
\text { democracia }\end{array}$} & \multicolumn{2}{|c|}{$\begin{array}{c}\text { Preferência pela } \\
\text { democracia }\end{array}$} & \multicolumn{2}{|c|}{ Igualitarismo } & \multicolumn{2}{|c|}{ Estatismo } \\
\hline & Anti-PT & Grupos & Anti-PT & Grupos & Anti-PT & Grupos & Anti-PT & Grupos \\
\hline -PT/-PSDB & - & $\begin{array}{l}1,115 \\
(, 163)\end{array}$ & - & $\begin{array}{l}1,125 \\
(, 189)\end{array}$ & - & $\begin{array}{l}1,418^{*} \\
(, 161)\end{array}$ & - & $\begin{array}{l}, 874 \\
(, 163)\end{array}$ \\
\hline -PT/ØPSDB & - & $\begin{array}{l}1,020 \\
(, 191)\end{array}$ & - & $\begin{array}{l}950 \\
(, 220) \\
\end{array}$ & - & $\begin{array}{l}1,219 \\
(, 189)\end{array}$ & - & $\begin{array}{l}1543^{*} \\
(, 207)\end{array}$ \\
\hline -PT/+PSDB & - & $\begin{array}{l}1,007 \\
(, 246) \\
\end{array}$ & - & $\begin{array}{l}, 861 \\
(, 275) \\
\end{array}$ & - & $\begin{array}{l}1,193 \\
(, 241) \\
\end{array}$ & - & $\begin{array}{l}, 918 \\
(, 249) \\
\end{array}$ \\
\hline $\begin{array}{l}\text { Cox e Snell } \\
\text { Nagelkerke }\end{array}$ & $\begin{array}{l}007 \\
, 010\end{array}$ & $\begin{array}{l}010 \\
, 014\end{array}$ & $\begin{array}{l}010 \\
, 015\end{array}$ & $\begin{array}{l}011 \\
, 017\end{array}$ & $\begin{array}{l}, 013 \\
, 018\end{array}$ & $\begin{array}{l}, 012 \\
, 017\end{array}$ & $\begin{array}{l}002 \\
, 003\end{array}$ & $\begin{array}{l}, 008 \\
, 012\end{array}$ \\
\hline
\end{tabular}

Fonte: Esebs (de 2002 a 2014).

Nota: Os valores correspondem aos $\operatorname{Exp}(B)$ e entre parênteses são apresentados os erros padronizados.

$*$ Sig. $=0,000 . * *$ Sig. $\leq 0,05$.

$" a "$ = categoria de referência.

Outra variável atitudinal a ser analisada é o "igualitarismo". Essa variável foi construída a partir de duas perguntas que têm como elemento central a questão da igualdade (ver operacionalização da variável no Apêndice 1). Na Tabela 7 vemos que a variável que distingue os antipetistas dos demais eleitores não está relacionada a posturas mais ou menos igualitaristas. Nesse primeiro modelo apenas a faixa etária e o grupo étnico se mostraram relevantes, inclusive com impactos negativos semelhantes. Indivíduos mais velhos tendem a ser menos igualitaristas, assim como os brancos. No modelo que contrasta os grupos de antipetistas, esse efeito do grupo étnico persiste, mas não o da idade. Nesse modelo, pela primeira vez, um dos grupos gerados pelas posições em relação aos partidos aparece como preditor relevante. O grupo dos antipetistas que também avaliam mal o PSDB tem sua chance de ser igualitarista elevada em mais de $40 \%$.

Os últimos modelos da Tabela 7 apresentam os resultados de análise semelhante para a variável atitudinal estatismo, criada a partir de duas questões que buscam captar as preferências do eleitorado por mais ou menos ação do Estado na economia e na garantia do bem-estar dos indivíduos (ver operacionalização da variável no Apêndice 2). A única variável do modelo que se mostrou relevante foi o antipetismo; mais especificamente, eleitores antipetistas que se manifestam de maneira neutra em relação ao PSDB são menos estatistas do que os não antipetistas.

\section{Sentimentos partidários e voto}

Nesta seção analisamos os possíveis efeitos dos sentimentos manifestados pelos eleitores em relação a PT e PSDB na sua decisão de voto na eleição presidencial de 2014. Começamos por apresentar um modelo probit incluindo a variável relativa ao antipetismo em sua forma mais desagregada (em três subgrupos). O objetivo é tentar captar os efeitos diretos do antipetismo sobre o voto, de maneira a diferenciar os subgrupos em questão. A seguir, utilizamos a variável que sintetiza o conjunto de sentimentos 
(positivos e negativos) em relação ao PT e ao PSDB simultaneamente (ver Tabela 3). Inicialmente apresentamos um cruzamento simples entre essa variável e o voto no $1^{\circ} \mathrm{e}$ 20 turnos da eleição presidencial, de forma a ter uma primeira aproximação da associação entre os sentimentos partidários dos eleitores em relação às duas legendas (simultaneamente) e seu voto. Por fim, apresentamos um modelo multivariado (probit) em que essa medida é um dos preditores.

A Tabela 8 mostra dados sobre a relação entre a avaliação que os eleitores faziam a respeito dos dois principais partidos na disputa eleitoral presidencial (na forma de notas dadas a eles) e seu voto. A partir da avaliação simultânea de PT e PSDB, criamos um conjunto de categorias, que tem em um extremo (ponto 1) os eleitores que avaliavam positivamente o PT e negativamente o PSDB e, no outro extremo (ponto 7), os eleitores que avaliavam negativamente o PT e positivamente o PSDB. Os dados indicam que a avaliação dos partidos feita pelos eleitores tem forte associação com seu voto. Entre eleitores que avaliaram positivamente o PT e negativamente o PSDB, Dilma venceu Aécio por uma diferença de $77 \%$ no $1{ }^{\circ}$ turno e $90 \%$ no $2^{\circ}$ turno; essa diferença cai à medida que passamos para outros grupos de eleitores, invertendo a situação para uma vitória pró-Aécio de $49 \%$ no 10 turno (e $78 \%$ no 20 turno) entre os eleitores com avaliação negativa do PT e neutra do PSDB (ponto 5 da escala), até chegar a uma diferença pró-Aécio de $72 \%$ no $1^{\circ}$ turno (e $86 \%$ no 20 turno) entre eleitores que avaliavam negativamente o PT e (simultaneamente) positivamente o PSDB. 
Tabela 8

Voto em Dilma e Aécio, segundo notas atribuídas a PT e PSDB (\%)

(Presidente - $1^{\circ}$ e $2^{\circ}$ turnos - Eseb 2014)

\begin{tabular}{|c|c|c|c|c|c|c|c|c|}
\hline \multirow{3}{*}{$\begin{array}{c}\text { Categorias } \\
\text { de } \\
\text { avaliação } \\
\text { PT/PSDB* }\end{array}$} & \multicolumn{8}{|c|}{ Candidato em que votou } \\
\hline & \multicolumn{4}{|c|}{10 turno } & \multicolumn{4}{|c|}{$2^{\circ}$ turno } \\
\hline & Dilma & Aécio & $\begin{array}{c}\text { Dif. } \\
\text { Pró- } \\
\text { Dilma }\end{array}$ & $\begin{array}{c}\text { (No } \\
\text { casos) }\end{array}$ & Dilma & Aécio & $\begin{array}{l}\text { Dif. } \\
\text { Pró- } \\
\text { Dilma }\end{array}$ & $\begin{array}{l}\left(\mathrm{N}^{\circ}\right. \\
\text { casos) }\end{array}$ \\
\hline 1 & 81 & 4 & 77 & $(298)$ & 95 & 5 & 90 & (269) \\
\hline 2 & 65 & 12 & 53 & $(235)$ & 84 & 16 & 68 & (209) \\
\hline 3 & 54 & 15 & 39 & $(136)$ & 83 & 17 & 66 & $(111)$ \\
\hline 4 & 38 & 26 & 12 & (772) & 56 & 44 & 12 & $(608)$ \\
\hline 5 & 8 & 57 & -49 & $(138)$ & 11 & 89 & -78 & $(125)$ \\
\hline 6 & 17 & 60 & -43 & $(102)$ & 23 & 77 & -54 & (93) \\
\hline 7 & 5 & 77 & -72 & $(250)$ & 7 & 93 & -86 & $(237)$ \\
\hline Total & 42 & 31 & 11 & $(1931)$ & 55 & 45 & 10 & (1652) \\
\hline
\end{tabular}

Fonte: Esebs (de 2002 a 2014).

*Categorias de avaliações de PT e PSDB (simultaneamente): 1 = avaliação positiva do PT e negativa do PSDB; 2 = avaliação positiva do PT e neutra do PSDB; 3 = avaliação neutra do PT e negativa do PSDB; 4 = "situações neutras"; 5 =avaliação negativa do PT e neutra do PSDB; 6 = avaliação neutra do PT e positiva do PSDB; 7 = avaliação negativa do PT e positiva do PSDB. Foram consideradas como "avaliação negativa" de um partido notas de 0 a 3; "avaliação neutra" notas de 4 a 6 e "avaliações positivas" notas de 7 a 10 . Foram consideradas "situações neutras" aquelas em que o eleitor manifestou a mesma avaliação (positiva, neutra ou negativa) em relação aos dois partidos simultaneamente. Foram desconsiderados na análise os entrevistados que informaram não ter votado, ou que responderam que não se lembravam em quem haviam votado, ou cuja resposta foi "não sabe" ou "não respondeu" à pergunta sobre o voto no $1{ }^{\circ}$ turno da eleição ou à pergunta sobre avaliação dos partidos.

Esses resultados são semelhantes aos encontrados para o período 2002-2010, utilizando indicador parecido, que levava em conta simultaneamente sentimentos positivos ("gosta do partido") e sentimentos negativos (rejeição) em relação aos dois partidos (Ribeiro, Carreirão e Borba, 2011). Da mesma forma, mantém-se a tendência de os candidatos do PSDB terem vitórias por maior diferença em relação a seus adversários petistas entre os eleitores com avaliação negativa (rejeição) para o PT e (simultaneamente) avaliação neutra para o PSDB do que entre os eleitores com avaliações positivas para o PSDB e neutras em relação ao PT. Vale dizer: para a escolha de candidatos pessedebistas nas eleições presidenciais, a rejeição ao PT pesa mais do que adesão ao PSDB por parte dos eleitores. Essa é uma análise preliminar com base em estatística descritiva. A análise multivariada a seguir permitirá verificar se esse forte impacto dos sentimentos partidários sobre a decisão de voto para presidente se mantém, ao serem incluídas outras variáveis.

A Tabela 9 apresenta os resultados de análise de regressão multinomial probit em que a variável dependente é o voto para presidente no 10 turno em 2014 (categoria 
de referência: voto em Dilma), incluindo como explicativas algumas medidas sociodemográficas e a variável relativa ao antipetismo em que os três subgrupos internamente a esse grupo são diferenciados. Não continuamos utilizando modelos logísticos nessa parte do artigo porque, apesar de muitos estudos sobre comportamento eleitoral empregarem essa metodologia, ela viola a importante suposição da independência de alternativas irrelevantes, segundo a qual a inclusão de um terceiro candidato não altera a razão das probabilidades de voto em dois candidatos iniciais (Long, 1997; Alvarez e Nagler, 1998; Pereira, 2014b). Entendemos que essa crença seja no mínimo irrealista, portanto, optamos por utilizar um modelo multinomial que utiliza um estimador probit, que considera todo o conjunto de alternativas sem pressupor tal independência. Com esse novo modelo é importante destacar que, diferentemente das tabelas anteriores com regressões logísticas, nas Tabelas 9 e 10 são apresentados coeficientes e não os exponenciais de B e, dessa forma, a interpretação deve principalmente se fixar no sinal positivo ou negativo dos efeitos e, obviamente, nos seus testes de significância estatística ${ }^{26}$. Para facilitar a interpretação dos efeitos, entretanto, foram calculados também os efeitos marginais de cada um dos preditores para os quatro resultados possíveis de nossa variável dependente. A interpretação dos efeitos marginais é feita de forma semelhante à interpretação dos coeficientes da regressão logística. Cada coluna relativa aos candidatos à presidência então se divide em duas outras colunas, com os efeitos marginais na segunda.

Considerando que a referência é o voto em Dilma e iniciando pelas nossas variáveis centrais, podemos identificar efeitos significativos e consistentes em todos os grupos de antipetismo.

\footnotetext{
${ }^{26}$ A interpretação dos coeficientes do probit é bastante diferente dos modelos logísticos, já que os coeficientes não refletem diretamente o incremento de probabilidade de escolha da categoria da dependente a cada elevação da escala da independente. Esse coeficiente varia em razão dos valores em cada preditor adicionado ao modelo.
} 
Tabela 9

Regressão multinomial probit para a eleição presidencial de 2014

\begin{tabular}{|c|c|c|c|c|c|c|c|c|}
\hline & \multicolumn{2}{|c|}{ Dilma } & \multicolumn{2}{|c|}{ Aécio } & \multicolumn{2}{|c|}{ Marina } & \multicolumn{2}{|c|}{ Outros } \\
\hline & Coef & Marg. & Coef. & Marg. & Coef. & Marg. & Coef. & Marg. \\
\hline Sexo & - & $\begin{array}{r}, 007 \\
(, 025)\end{array}$ & $\begin{array}{l}, 080 \\
(, 092)\end{array}$ & $\begin{array}{c}, 045 \\
(, 024)\end{array}$ & $\begin{array}{l}-, 251^{*} \\
(, 106)\end{array}$ & $\begin{array}{l}-, 052 * \\
(, 017)\end{array}$ & $\begin{array}{l}-0,016 \\
(, 168)\end{array}$ & $\begin{array}{l}1000 \\
(, 007)\end{array}$ \\
\hline Faixa etária & - & $\begin{array}{r}, 000 \\
(, 009)\end{array}$ & $\begin{array}{l}, 020 \\
(, 032)\end{array}$ & $\begin{array}{l}, 010 \\
(, 009)\end{array}$ & $\begin{array}{l}-, 017 \\
(, 037)\end{array}$ & $\begin{array}{l}-, 004 \\
(, 006)\end{array}$ & $\begin{array}{l}-, 126 * \\
(, 061)\end{array}$ & $\begin{array}{l}-, 006 * \\
(, 003)\end{array}$ \\
\hline Escolaridade & - & $\begin{array}{l}-, 036 * * \\
(, 006)\end{array}$ & $\begin{array}{l}, 109 * * \\
(, 023)\end{array}$ & $\begin{array}{l}, 019 * \\
(, 006) \\
\end{array}$ & $\begin{array}{l}142 * * \\
(, 027) \\
\end{array}$ & $\begin{array}{l}, 016 * * \\
(, 004)\end{array}$ & $\begin{array}{l}, 092^{*} \\
(, 044) \\
\end{array}$ & $\begin{array}{l}, 001 \\
(, 002) \\
\end{array}$ \\
\hline $\begin{array}{l}\text { Grupo étnico } \\
\text { (branco) }\end{array}$ & - & $\begin{array}{c}-, 079 * \\
(, 025)\end{array}$ & $\begin{array}{l}\text {,371** } \\
(, 094)\end{array}$ & $\begin{array}{l}1,104 * * \\
(, 025)\end{array}$ & $\begin{array}{l}035 \\
(, 109)\end{array}$ & $\begin{array}{l}-, 026 \\
(, 017)\end{array}$ & $\begin{array}{l}188 \\
(, 173)\end{array}$ & $\begin{array}{c}1002 \\
(, 008)\end{array}$ \\
\hline $\begin{array}{l}\text { Interesse } \\
\text { por política }\end{array}$ & - & $\begin{array}{r}, 005 \\
(, 014) \\
\end{array}$ & $\begin{array}{l}-, 050 \\
(, 054)\end{array}$ & $\begin{array}{l}-, 019 \\
(, 014)\end{array}$ & $\begin{array}{c}, 015 \\
(, 061) \\
\end{array}$ & $\begin{array}{c}, 005 \\
(, 010) \\
\end{array}$ & $\begin{array}{c}, 145 \\
(, 095)\end{array}$ & $\begin{array}{c}, 007 \\
(, 004) \\
\end{array}$ \\
\hline $\begin{array}{l}\text { Não } \\
\text { antipetista }\end{array}$ & - & $a$ & $a$ & $a$ & $a$ & $a$ & $a$ & $a$ \\
\hline -PT/-PSDB & - & $\begin{array}{l}-, 253 * * \\
(, 027)\end{array}$ & $\begin{array}{l}939 * * \\
(, 120) \\
\end{array}$ & $\begin{array}{l}187 * * \\
(, 033) \\
\end{array}$ & $\begin{array}{l}827 * * \\
(, 136)\end{array}$ & $\begin{array}{l}, 060 * \\
(, 026) \\
\end{array}$ & $\begin{array}{l}692 * \\
(, 213) \\
\end{array}$ & $\begin{array}{l}005 \\
(, 010) \\
\end{array}$ \\
\hline -PT/ØPSDB & - & $\begin{array}{l}-457 * * \\
(, 018)\end{array}$ & $\begin{array}{c}2,443 * \\
* \\
(, 202)\end{array}$ & $\begin{array}{l}, 416 * * \\
(, 036)\end{array}$ & $\begin{array}{c}1,906 * * \\
(, 221)\end{array}$ & $\begin{array}{l}, 043 \\
(, 032)\end{array}$ & $\begin{array}{c}1,645^{* *} \\
(, 324)\end{array}$ & $\begin{array}{l}-, 002 \\
(, 011)\end{array}$ \\
\hline -PT/+PSDB & - & $\begin{array}{l}-, 541 * * \\
(, 015)\end{array}$ & $\begin{array}{c}3,064^{*} \\
* \\
(, 180)\end{array}$ & $\begin{array}{c}, 572 * * \\
(, 024)\end{array}$ & $\begin{array}{c}1,935 * * \\
(, 202)\end{array}$ & $\begin{array}{l}-, 019 \\
(, 021)\end{array}$ & $\begin{array}{c}1,611 * * \\
(, 306)\end{array}$ & $\begin{array}{l}-, 013 \\
(, 007)\end{array}$ \\
\hline
\end{tabular}

Fonte: Esebs (de 2002 a 2014).

Notas: Os valores correspondem aos B (e não aos Exp (B)) e entre parênteses são apresentados os erros padronizados. $*$ Sig. $=0,000$. $* *$ Sig. $\leq 0,05$.

Categoria de referência $=$ Dilma.

Probit qui-quadrado $=, 000 ;$ Wald $=538,04 ; \mathrm{N}=1997$.

"a" = categoria de referência.

Os impactos menos expressivos, como poderia ser antecipado, são verificados no contraste entre os não antipetistas e aqueles que apresentam disposições negativas em relação aos dois partidos. Ainda assim, é preciso considerar que esse grupo apresenta maior probabilidade de votar em Aécio, Marina e outros candidatos. Consistentemente, essa diferença é menor na comparação entre Dilma e Aécio, mas vai aumentando no confronto com Marina e outros candidatos. Analisando os efeitos marginais desse grupo, constatamos redução de $25 \%$ na chance de votar em Dilma, tomando sempre como referência os "não antipetistas". De forma inversa, o pertencimento a esse grupo eleva a probabilidade de voto em Aécio em 18,7\%, o que claramente indica que o elemento mais relevante é a rejeição ao PT, já que, mesmo avaliando negativamente o PSDB, continuam preferindo o candidato dessa legenda na comparação. O voto em Marina é bem menos impactado, mas ainda assim o seu efeito é positivo, com os pertencentes a esse grupo apresentando incremento de $6 \%$ na probabilidade.

Os efeitos são bem mais expressivos quando consideramos o grupo dos que são antipetistas e neutros em relação ao PSDB. Como esperado, esses eleitores apresentam maior probabilidade de voto em Aécio do que em Dilma, se comparado com o grupo dos "não antipetistas", e essa diferença vai caindo quando a comparação muda para o voto 
em Marina e outros. Os eleitores desse grupo têm sua chance de voto em Dilma reduzida em $45,7 \%$, enquanto essa mesma probabilidade se eleva em $41,6 \%$ no caso do voto em Aécio. Esse grupo não se diferencia dos "não antipetistas" no que diz respeito à probabilidade de voto em Marina e outros candidatos.

Essa tendência é definitivamente confirmada quando consideramos o último grupo, dos antipetistas que são favoráveis ao PSDB. Nesse grupo o efeito é o mais elevado de todos os contrastes, indicando que esses eleitores apresentam a maior probabilidade de votar em Aécio (em vez de votar em Dilma) de todo o modelo. Coerentemente, essas diferenças de probabilidade caem quando a comparação vai para o voto em Marina e nos outros candidatos. Considerando os efeitos marginais, identificamos que os membros desse grupo têm sua chance de votar em Dilma reduzida em 54\% e, coerentemente, têm 57,2\% mais chance de voto em Aécio. O grupo não se diferencia no caso do voto em Marina e outros. Quanto ao voto em Marina, cabe assinalar que, quando os antipetistas são neutros ou avaliam positivamente o PSDB, não foi constatado nenhum efeito significativo; é apenas entre os eleitores que avaliam mal simultaneamente o PT e o PSDB que aumentam suas chances de voto.

Como temos defendido também a utilidade de medidas que avaliem conjuntamente sentimentos positivos e negativos, finalmente apresentamos (na Tabela 10) os resultados de modelo semelhante ao anterior, porém substituindo os grupos de antipetismo pela medida que leva em consideração os sentimentos em relação a PT e PSDB simultaneamente e reportada anteriormente na Tabela 3. Confirmando a tendência verificada nas análises anteriores desta seção, verificamos efeitos marginais negativos dessa variável sobre o voto em Dilma e positivos sobre o voto em Aécio. Cada ponto na escala dessa variável, que, na medida em que avança, se afasta do PT e se aproxima do PSDB, reduz pouco mais de $19 \%$ a chance de voto na candidata petista, enquanto avanços semelhantes incrementam a chance de voto no candidato do PSDB em 16,8\%. Apesar de bem menores, também podemos perceber efeitos positivos significativos $(2,2 \%)$ para o voto em Marina. 
Tabela 10

Regressão multinomial probit para a eleição presidencial de 2014

\begin{tabular}{|l|c|c|c|c|c|c|c|c|}
\hline & \multicolumn{2}{|c|}{ Dilma } & \multicolumn{2}{c|}{ Aécio } & \multicolumn{2}{c|}{ Marina } & \multicolumn{2}{c|}{ Outros } \\
\cline { 2 - 9 } & Coef. & Marg. & Coef. & Marg. & Coef. & Marg. & Coef. & Marg. \\
\hline Sexo & - &, 021 &, 044 &, 036 &,$- 286 *$ &,$- 057^{*}$ &,- 041 &,- 000 \\
& & $(, 026)$ & $(, 096)$ & $(, 024)$ & $(, 107)$ & $(, 018)$ & $(, 170)$ & $(, 008)$ \\
\hline Faixa etária & - &, 001 &, 018 &, 008 &,- 018 &,- 004 &,$- 127^{*}$ &,$- 006^{*}$ \\
& & $(, 009)$ & $(, 034)$ & $(, 009)$ & $(, 038)$ & $(, 006)$ & $(, 062)$ & $(, 003)$ \\
\hline Escolaridade & - &,$- 036 * *$ &, $110 * *$ &, $019 *$ &, $140 * *$ &, $017 * *$ &, $089 *$ &, 001 \\
& & $(, 007)$ & $(, 025)$ & $(, 006)$ & $(, 027)$ & $(, 004)$ & $(, 044)$ & $(, 002)$ \\
\hline $\begin{array}{l}\text { Grupo étnico } \\
\text { (branco) }\end{array}$ & - &,$- 061^{*}$ &, $310 *$ & $, 08)^{*}$ &,- 014 &,- 029 &, 148 &, 002 \\
\hline $\begin{array}{l}\text { Interesse } \\
\text { por política }\end{array}$ & - & $(, 027)$ & $(, 099)$ & $(, 025)$ & $(, 061)$ & $(, 018)$ & $(, 175)$ & $(, 008)$ \\
\hline Avaliação & - &,- 004 &,- 046 &,- 017 &, 014 &, 005 &, 151 &, 0010 \\
PT/PSDB & & $(, 015)$ & $(, 056)$ & $(, 014)$ & $(, 061)$ & $(, 010)$ & $(, 096)$ & $(, 004)$ \\
\hline
\end{tabular}

Fonte: Esebs (de 2002 a 2014).

Notas: Os valores correspondem aos B (e não aos $\operatorname{Exp}(B)$ ) e entre parênteses são apresentados os erros padronizados. $*$ Sig. $=0,000$. $* *$ Sig. $\leq 0,05$.

Categoria de referência $=$ Dilma.

Probit qui-quadrado $=, 000 ;$ Wald $=523,87 ; \mathrm{N}=1997$.

O conjunto desses resultados mostra forte relação entre as disposições dos eleitores em relação a esses dois grandes partidos nacionais e seu comportamento eleitoral no último pleito presidencial. Não apenas o antipetismo se mostrou recorrentemente relevante diante de importantes controles como escolaridade, sexo e idade, mas também os grupos de antipetismo apresentam efeitos que se distinguem em sentidos coerentes com nossas hipóteses e expectativas teóricas.

\section{Considerações finais}

O artigo analisou os sentimentos partidários dos eleitores brasileiros e seus correlatos atitudinais e comportamentais. Atenção especial foi dada ao tema do antipartidarismo, em especial ao sentimento "antipetista" de parcela do eleitorado brasileiro.

Os resultados apontam que, em termos longitudinais, verifica-se um declínio no sentimento de "gosto" do eleitor para com os partidos brasileiros em 2014 (26,2\% da amostra diz gostar de algum partido), o menor nível verificado em todas as rodadas do Eseb. Tal declínio foi capitaneado principalmente pelo PT, que também teve sua pior avaliação desde 2002 (18\% dizem gostar do partido em 2014 contra quase 28\% em 2010).

Também propusemos uma mensuração dos sentimentos partidários através de uma escala das notas aos dois principais partidos brasileiros (PT e PSDB) e a análise mostrou que em 2014 a vantagem pró-PT foi a menor da série histórica iniciada em 2002, especialmente nas posições mais extremas da escala ( $15 \%$ de eleitores com avaliação simultaneamente positiva do PT e negativa do PSDB, contra $13 \%$ na situação 
inversa). Houve, enfim, uma mudança nos sentimentos partidários dos eleitores entre 2010 e 2014 que representou uma melhora da situação do PSDB, em detrimento da do PT, embora este ainda continuasse numa situação um pouco melhor do que a de seu adversário.

Considerando que nosso foco central é o antipetismo, verificamos que os sentimentos negativos para com o partido têm aumentado e que o eleitor antipetista tende a ocupar um lugar mais central na estrutura social (em termos de escolaridade e cor), quando comparado com o eleitor petista ou neutro em relação a esse partido. Isso vale especialmente para o grupo de antipetistas que avalia positivamente o PSDB; entre estes também é maior o interesse pela política do que entre os eleitores que não são antipetistas - que, por sua vez, têm maior interesse pela política do que os eleitores que avaliam mal o PT e o PSDB simultaneamente.

Quando verificamos os correlatos atitudinais dos sentimentos partidários em relação a esses partidos, observa-se que o cenário de indiferenciação atitudinal, que vinha se afirmando desde 2002, continua crescendo em 2014 em relação às variáveis em análise (igualitarismo, estatismo, adesão à democracia e preferência pela democracia). Vale dizer, não há diferenças significativas entre as atitudes dos eleitores antipetistas (seja qual for sua avaliação referente ao PSDB) e as atitudes dos demais eleitores.

Quando incluímos os sentimentos partidários nos modelos de decisão do voto, verificamos que eles são fortes preditores do comportamento eleitoral. O antipetismo se mostrou um forte preditor: as chances de voto em Aécio são maiores do que as chances de voto em Dilma em qualquer dos subgrupos de eleitores antipetistas, sobretudo entre aqueles que avaliam positivamente o PSDB. Quanto a Marina, é apenas entre os eleitores que avaliam mal simultaneamente o PT e o PSDB que aumentam suas chances de voto, o que está em acordo com a hipótese de que a candidata é uma opção preferencial dos eleitores que rejeitam a polarização PT-PSDB na política nacional. Utilizando a "escala" de sete pontos, considerando os sentimentos favoráveis e contrários ao PT e ao PSDB simultaneamente, constatamos também uma forte influência dos sentimentos partidários sobre a decisão de voto na eleição presidencial de 2014: à medida que passamos do extremo mais favorável ao PT para o mais favorável ao PSDB, crescem significativamente as chances de voto em Aécio, comparativamente ao voto em Dilma, mesmo controlando por variáveis sociodemográficas e grau de interesse pela política.

Ressalvando que nossos dados não permitem avaliar a estabilidade dos sentimentos partidários dos eleitores brasileiros - tema sobre o qual há poucos estudos e não há consenso -, os resultados mais gerais do presente artigo mostram, portanto, que os sentimentos partidários do eleitorado brasileiro tiveram impacto significativo sobre seu voto nas eleições presidenciais brasileiras de 2014.

De um ponto de vista substantivo, a constatação de que a rejeição partidária é uma variável importante sugere que os partidos menos afetados por escândalos de corrupção ou por avaliações muito negativas de seus desempenhos ao exercer cargos 
executivos podem ser um ativo eleitoral importante, especialmente na conjuntura que estamos atravessando. Outro ponto que cabe destacar é que nossos achados não corroboram a tese de que no Brasil o único impacto significativo dos sentimentos partidários dos eleitores sobre o voto teria sido, até aqui, o petismo (ou seja, a simpatia pelo PT) - tese que se apoia no fato de que a simpatia pelos demais partidos vinha sendo quantitativamente pouco relevante nas últimas décadas. Nem nos parece que caiba postular que o antipetismo vá representar no futuro próximo o único sentimento partidário relevante na decisão de voto dos brasileiros. Nossos resultados, assim como os que havíamos encontrado em trabalho anterior (Ribeiro, Carreirão e Borba, 2011), mostram que, pelo menos no que diz respeito às eleições presidenciais polarizadas por PT e PSDB, contaram tanto os sentimentos positivos quanto os negativos em relação aos dois partidos. E, quando consideramos o conjunto desses sentimentos, os eleitores aí envolvidos não são apenas os cerca de $20 \%$ a $25 \%$ de eleitores petistas (dados que persistiram até 2014), mas percentuais entre $57 \%$ e quase $70 \%$ (entre 2002 e 2014; ver Tabela 3). Embora a força desses sentimentos sobre o voto varie (sendo maior entre os eleitores que se situam nos pontos extremos da "escala" de sete pontos que construímos), os dados mostram que esse conjunto de sentimentos impacta a decisão de voto nessas eleições. É difícil prever o que virá nos próximos anos em relação ao sistema partidário brasileiro; os impactos da atual crise política podem vir a modificar significativamente os sentimentos dos eleitores em relação a esses partidos e podem mesmo levar ao fim dessa polarização nas eleições presidenciais. De toda forma, acreditamos que, quaisquer que sejam os desdobramentos, é importante continuar considerando os sentimentos (positivos e negativos) dos eleitores em relação aos partidos como um dos elementos importantes de sua decisão de voto no futuro.

Do ponto de vista metodológico, a medida utilizada por nós para avaliar o impacto dos sentimentos partidários dos eleitores sobre seu voto nos levou a resultados que corroboram achados anteriores, o que parece indicar que essa medida tem validade. Os achados empíricos de nosso artigo reafirmam, porém, alguns desafios analíticos para os estudos sobre partidarismo. O principal deles está relacionado à necessidade já levantada por Garry (2007) de investir em novas formas de mensurar a identificação partidária, em especial, para os contextos de multipartidarismo. E, nesses casos, devemse considerar tanto a possibilidade de identificação positiva como a negativa com múltiplos partidos. Do ponto de vista mais operacional, é importante também uma avaliação mais sistemática sobre o rendimento analítico dos diferentes indicadores que vêm sendo utilizados no Brasil para mensurar os sentimentos dos eleitores em relação aos partidos (preferência partidária; partido de que o eleitor gosta; partido que representa a maneira como o eleitor pensa; partido em que não votaria; avaliação através de notas - dos diferentes partidos etc.). O impacto significativo dos sentimentos partidários sobre a decisão de voto na eleição presidencial brasileira - apontado em 
vários estudos e reiterado pelas conclusões do presente artigo - reforça a relevância do enfrentamento desses desafios analíticos.

Ednaldo Ribeiro - Professor do Programa de Pós-Graduação em Ciências Sociais da Universidade Estadual de Maringá e do Programa de Pós-Graduação em Ciência Política da Universidade Federal do Paraná. E-mail: <ednaldoribeiro@icloud.com>.

Yan Carreirão - Professor do Programa de Pós-Graduação em Sociologia Política da Universidade Federal de Santa Catarina. E-mail: <yancarreirao@uol.com.br>.

Julian Borba - Professor do Programa de Pós-Graduação em Sociologia Política da Universidade Federal de Santa Catarina. E-mail: <julian.borba@ufsc.br>.

\section{Referências bibliográficas}

Almeida, A. A cabeça do eleitor: estratégia de campanha, pesquisa e vitória eleitoral. Rio de Janeiro: Record, 2008.

AlmeidA, J. Como vota o brasileiro. São Paulo: Casa Amarela, 1996.

Almond, G.; VerbA, S. The civic culture. Newbury Park: Sage, 1989.

Alvarez, M.; NAgler, J. "When politics and models collide: estimating models of multiparty elections". American Journal of Political Science, vol. 42, no 1, pp. 55-96, 1998.

BAKER, A., et al. "The dynamics of partisan identification when party brands change: the case of the Workers Party in Brazil". Journal of Politics, vol. 78, n 1, p. 197-213, 2016.

BAUmeister, R., et al. "Bad is stronger than good". Review of General Psychology, vol. 5, no 4, p. 323-370, 2001.

BragA, M. S. "Eleições e democracia no Brasil: a caminho de partidos e sistema partidário institucionalizados". Revista Brasileira de Ciência Política, no 4, p. 43-73, 2010.

BRAgA, M. S.; Pimentel JR., J. "Os partidos políticos brasileiros realmente não importam?". Opinião Pública, vol. 17, no 2, p. 271-303, 2011.

CAmpbell, A., et al. The American voter. New York: Wiley, 1960.

CARreirão, Y. A decisão de voto nas eleições presidenciais brasileiras. Rio de Janeiro/Florianópolis: Editora da FGV/EDUFSC, 2002.

. "Relevant factors for the voting decision in the 2002 presidential election: an analysis of the Eseb (Brazilian Electoral Study) data". Brazilian Political Science Review, vol. 1, no 1, p. 70-101, $2007 a$.

. "Identificação ideológica, partidos e voto na eleição presidencial de 2006". Opinião Pública, vol. 13, no 2, p. 307-339, 2007b.

CARREIRÃO, Y. "Opiniões políticas e sentimentos partidários dos eleitores brasileiros". Opinião Pública, vol. 14, no 2, p. 319-351, 2008. 
CARREIRÃo, Y.; BARBETtA, P. "A eleição presidencial de 2002: a decisão de voto na região da Grande São Paulo". Revista Brasileira de Ciências Sociais, nº 56, p. 75-93, 2004.

CARREIRÃo, Y.; KInZo, M. D. "Partidos políticos, preferência partidária e decisão eleitoral no Brasil (1989/2002)". Dados, vol. 47, no 1, p. 131-168, 2004.

CASTRO, M. M. "Sujeito e estrutura no comportamento eleitoral". Revista Brasileira de Ciências Sociais, no 20, p. 7-19, 1992.

Clarke, H.; Stewart, M. "The decline of the parties in the minds of citizens". Annual Review of Political Science, vol. 1, p. 357-378, 1998.

CONVERSE, P. The nature of belief systems in mass publics. In: APTER, D. (ed.). Ideology and discontent. New York: Free Press, 1964.

Dalton, R.; WATtenberg, M. "The not so simple act of voting". In: Finifter, A. (ed.). State of political science II. Washington: American Political Science Association, 1993.

. (eds.). Parties without partisans: political change in advanced industrialized democracies. Oxford: Oxford University Press, 2001.

Downs, A. An economic theory of democracy. New York: Harper \& Row Publishers, 1957.

EASTON, D. A. Framework for political analysis. New Jersey: Prentice-Hall, 1963.

Figueiredo, M. A decisão do voto. São Paulo: Idesp/Sumaré, 1991.

FIORINA, M. Retrospective voting in American national elections. New Haven: Yale University Press, 1981.

GARRY, J. "Making 'party identification' more versatile: operationalizing the concept for the multiparty setting". Electoral Studies, nº 26, p. 346-358, 2007.

Greene, S. "Understanding party identification. A social identity approach". Political Psychology, vol. 20, no 2, p. 393-403, 1999.

HUNTER, W.; POWER, T. "Rewarding Lula: Executive power, social policy, and the Brazilian elections of 2006". Latin American Politics \& Society, vol. 49, n 1, p. 1-30, 2007.

KINZO, M. D. "Os partidos no eleitorado: percepções públicas e laços partidários no Brasil". Revista Brasileira de Ciências Sociais, vol. 19, no 54, p. 65-80, 2005.

KLINGEMANN, H.-D.; WATTENBERG, M. P. "Decaying versus developing party systems: a comparison of party images in the United States and West Germany". British Journal of Political Science, vol. 22, n० 2, p. 131-149, 1992.

Lamounier, B.; Meneguello, R. Partidos políticos e consolidação democrática. O caso brasileiro. São Paulo: Brasiliense, 1986.

LAVARedA, A. "Governos, partidos e eleições segundo a opinião pública: o Brasil de 1989 comparado ao de 1964". Dados, vol. 32, no 3, pp. 341-362, 1989.

A democracia nas urnas: o processo partidário eleitoral brasileiro. Rio de Janeiro: Rio Fundo/Iuperj, 1991.

. Emoções ocultas e estratégias eleitorais. Rio de Janeiro: Objetiva, 2009.

LONG, S. Regression models for categorical and limited dependent variables. London: Sage Publications, 1997.

MAINWARING, S. "Políticos, partidos e sistemas eleitorais. O Brasil numa perspectiva comparada". Novos Estudos Cebrap, n 29, p. 34-58, 1991.

MAINWARING, S. Sistemas partidários em novas democracias: o caso do Brasil. Porto Alegre/Rio de Janeiro: Mercado Aberto/Ed. FGV, 2001. 
Medeiros, M.; NöEL, A. "The forgotten side of partisanship: negative party identification in four Anglo-American democracies". Comparative Political Studies, vol. 47, no 7, p. 1.022-1.046, 2014.

Mendes, M.; VentURI, G. "Eleição presidencial: o Plano Real na sucessão de Itamar Franco". Opinião Pública, vol. 2, n² 2, p. 59-72, 1994.

MONDAK, J. J., et al. "The participatory personality: evidence from Latin America". British Journal of Political Science, no 41, p. 211-221, 2010.

NEVES, L. S. "Preferência partidária na perspectiva do eleitorado brasileiro: mudanças e perpetuidades após as eleições presidenciais de 2002". Monografia em Ciência Política. UnB, Brasília, 2012.

Nicolau, J.; Peixoto, V. "Uma disputa em três tempos: uma análise das bases municipais das eleições presidenciais de 2006". In: 310 Encontro Anual da Anpocs, Caxambu-MG, 2007.

Paiva, D.; Braga, M. S; Pimentel JR., J. "Eleitorado e partidos políticos no Brasil". Opinião Pública, vol. 13, no 2, p. 388-408, 2007.

PereirA, F. B. "A estabilidade e a efetividade da preferência partidária no Brasil". Revista Brasileira de Ciência Política, vol. 13, p. 213-244, 2014a.

. Voto econômico retrospectivo e sofisticação política na eleição presidencial de 2002".

Revista de Sociologia e Política, vol. 22, no 50, p. 149-174, 2014b.

Pimentel JR., J. "Razão e emoção no voto: o caso da eleição presidencial de 2006". Dissertação de Mestrado em Ciência Política. USP, São Paulo, 2007.

REIS, F. W. "A razão do eleitor. Resenha de Esquerda e Direita no Eleitorado Brasileiro, de André Singer (São Paulo, Edusp, 2000)". Jornal de Resenhas (Folha de S. Paulo), São Paulo, 9 set. 2000.

ReNNó, L. "Escândalos e voto: as eleições presidenciais brasileiras de 2006". Opinião Pública, vol. 13, no 2, p. 260-282, 2007.

RenNó, L.; CABello, A. "As bases do lulismo: a volta do personalismo, realinhamento ideológico ou não alinhamento?". Revista Brasileira de Ciências Sociais, vol. 25, p. 39-60, 2010.

Ribeiro, E.; CARREIRÃo, Y.; Borba, J. "Sentimentos partidários e atitudes políticas entre os brasileiros". Opinião Pública, vol. 17, nº 2, p. 333-368, 2011.

ROSE, R.; MISHLER, W. "Negative and positive party identification in post-communist countries". Electoral Studies, vol. 17, n 2, pp. 217-234, 1998.

Samuels, D. "As bases do petismo". Opinião Pública, vol. 10, no 2, p. 221-241, 2004.

. "A evolução do petismo (2002-2008)". Opinião Pública, vol. 14, no 2, p. 302-318, 2008.

Singer, A. Esquerda e direita no eleitorado brasileiro. São Paulo: Edusp, 2000.

2010.

. "A segunda alma do Partido dos Trabalhadores". Novos Estudos Cebrap, no 88, p. 89-111,

SOARES, G. A.; TERRON, S. L. "Dois Lulas: a geografia eleitoral da reeleição (explorando conceitos, métodos e técnicas de análise geoespacial)". Opinião Pública, vol. 14, n 2, p. 269-301, 2008.

SPECK, B.; BRAGA, M. S.; COSTA, V. "Estudo exploratório sobre filiação e identificação partidária no Brasil". Revista de Sociologia e Política, vol. 23, nº 56, p. 125-148, 2015.

TARouco, G. "Institucionalização partidária no Brasil (1982-2006)". Revista Brasileira de Ciência Política, no 4, p. 169-186, 2010.

TERRON, S. L.; SOARES, G. A. D. "As bases eleitorais de Lula e do PT: do distanciamento ao divórcio". Opinião Pública, vol. 16, no 2, p. 310-337, 2010.

VECCHIONE, M.; CAPRARA, G. V. "Personality determinants of political participation: the contributions of traits and self-efficacy beliefs". Personality and Individual Differences, no 46, p. 487-492, 2009. 
VEIGA, L. "Os partidos brasileiros na perspectiva dos eleitores: mudanças e continuidades na identificação partidária e na avaliação das principais legendas após 2002". Opinião Pública, vol. 13, no 2, p. 340-365, 2007.

. "O partidarismo no Brasil (2002/2010)". Opinião Pública, vol. 17, no 2, p. 400-425, 2011.

VENTURI, G. "PT 30 anos: crescimento e mudanças na preferência partidária. Impacto nas eleições de 2010". Perseu, no 5, p. 197-214, 2010.

WATTENBERG, M. The rise of candidate-centered politics (presidential elections of the 1980's).

Cambridge: Harvard University Press, 1991. Press, 1998.

. The decline of American political parties, 1952-1996. Cambridge: Harvard University

Zucco, C.; SAMUels, D. "Partisans, anti-partisans and voting behavior in Brazil", 2015 (work in progress). Disponível em: <http://www.fgv.br/professor/cesar.zucco/>.

\section{APÊNDICE 1}

\section{Operacionalização da variável atitudinal "igualitarismo"}

Foram usadas as respostas às seguintes questões do Eseb 2014, para construir a variável "igualitarismo":

PC13C - "Em qualquer situação as pessoas mais pobres devem ter mais chances do que as ricas" (escala de concordância com cinco pontos); e

PC13E - "As cotas reservadas para negros e índios prejudicam quem tem mais competência" (escala de concordância com cinco pontos).

A análise fatorial obteve $\mathrm{KMO}$ de 0,50 e os fatores carregam com cargas superiores a 0,8. 0 percentual de variação explicada com a extração de um único fator é de $66,3 \%$. Para a construção da medida de igualitarismo inicialmente foram recodificadas as respostas às duas questões agrupando as opções contrárias ao igualitarismo como " 0 ", as indiferentes como " 1 " e as favoráveis como " 2 ". Ao somar as duas variáveis, temos uma medida de 0 a 4 . A partir disso foi feita nova recodificação para transformar em uma variável dicotômica, pois seria a única forma de rodar modelo semelhante aos anteriores usando os grupos de antipetismo em contraposição aos "não antipetistas". Para isso, consideramos os indivíduos com escores de 0 a 2 como não igualitaristas e indiferentes e os com escores 3 e 4 como igualitaristas.

\section{APÊNDICE 2}

\section{Operacionalização da variável atitudinal "estatismo"}

Para a operacionalização da variável "estatismo", o procedimento foi em boa medida semelhante ao utilizado para operacionalizar a variável "igualitarismo", a partir das respostas às seguintes questões do Eseb 2010 (respostas na forma de escalas de 0 a 10):

PC12B - "Deveria haver mais iniciativa privada na indústria e no comércio" (0) X "Deveria haver mais participação do governo na indústria e no comércio" (10); e

PC12C - "O governo precisa se responsabilizar mais para garantir o sustento de todos" (0) X "As pessoas precisam se responsabilizar mais para garantir seu próprio sustento" (10).

A análise fatorial obteve $\mathrm{KMO}$ de 0,56 e os fatores carregam com cargas superiores a 0,7. 0 percentual de variação explicada com a extração de um único fator é de 64,5\%.

Primeiramente as variáveis foram recodificadas em razão dos seus sentidos em três grupos: Estatistas (de 8 a 10 na PC12B e de 1 a 3 na PC12C) = 2; Indiferentes (de 4 a 7 em ambas) = 1; Antiestatistas (de 1 a 3 na $\mathrm{PC} 12 \mathrm{~B}$ e de 8 a 10 na $\mathrm{PC} 12 \mathrm{C}$ ) $=0$. O resultado da soma das respostas às 
duas questões foi uma medida de 0 a 4 . Consideramos os indivíduos com escores de 0 a 2 como não estatistas e os com escores 3 e 4 como estatistas.

\section{APÊNDICE 3}

\section{Sintaxes dos modelos probit (Stata)}

a) Modelo com grupos de antipetistas (Tabela 9) mprobit Voto Sexo FaixaEtaria Escolaridade GrupoEtnico Interesse PTnegPSDBneg PTnegPSDBneutro PTnegPSDBpos

b) Efeitos marginais do modelo com grupos de antipetistas (Tabela 9) mfx compute, predict (outcome(1)) mfx compute, predict (outcome(2)) mfx compute, predict (outcome(3)) $m f x$ compute, predict (outcome(4)) $1=$ Dilma

2 = Aécio

$3=$ Marina

$4=$ Outros

c) Modelo com avaliação PT/PSDB (Tabela 10) mprobit Voto Sexo FaixaEtaria Escolaridade GrupoEtnico Interesse AvaliaPT_PSDB

d) Efeitos marginais do modelo com grupos de antipetistas (Tabela 10) mfx compute, predictAvaliaPT_PSDB.

\section{Resumo}

Sentimentos partidários e antipetismo: condicionantes e covariantes

O artigo investiga, a partir dos dados do Estudo Eleitoral Brasileiro, os sentimentos partidários dos eleitores brasileiros em 2014 e suas relações com dimensões atitudinais e comportamentais. Ênfase especial é dada ao antipetismo, ou seja, ao sentimento negativo que parcela crescente do eleitorado vem manifestando em relação ao PT. Além de analisar a evolução dessas disposições entre 2002 e 2014, o artigo procura identificar o perfil sociodemográfico dos eleitores antipetistas e o impacto dessas disposições negativas sobre variáveis atitudinais (estatismo, igualdade e democracia) e sobre o voto. Os resultados apontam para o decréscimo generalizado dos sentimentos positivos em relação aos partidos, com destaque para o PT. Também indicam efeitos reduzidos do antipetismo sobre atitudes políticas, mas sua forte influência sobre padrões de comportamento eleitoral.

Palavras-chave: sentimentos partidários; antipetismo; atitudes políticas; comportamento eleitoral; CSES-Eseb 2014

\section{Abstract}

Party feelings and antipetismo: constraints and covariates

Using data from the Brazilian Electoral Survey (Eseb), this article investigates the feelings toward parties of Brazilian voters in 2014 and their relations to attitudinal and behavioral variables. Special emphasis is placed on antipetismo, i.e. the negative feeling toward the Workers' Party (PT) that is present among a growing segment of Brazilian voters. In addition to analyzing the evolution of these feelings between 2002 and 2014, the present work seeks to identify the sociodemographic profile of 
antipetista voters and the impact of such negative feelings on attitudinal variables (statism, equality, and democracy) and on vote choice. The results of this study demonstrate that positive party feelings are decreasing, especially toward the PT. They also point to the limited effects of antipetismo on political attitudes, while evidencing its great influence on electoral behavior.

Keywords: party feelings; antipetismo; political attitudes; electoral behavior; CSES-Eseb 2014

\section{Resumen}

Sentimientos partidarios y antipetismo: condicionantes y co-variables

El artículo investiga, a partir de los datos del estudio electoral brasileño, los sentimientos partidistas de los votantes brasileños en 2014 y su relación con las dimensiones de actitud y comportamiento. Se presta especial atención al antipetismo, es decir, el sentimiento negativo que la creciente parte del electorado está manifestando en relación con el PT. Además de la evolución de esas disposiciones entre 2002 y 2014, el análisis busca identificar el perfil sociodemográfico de los votantes antipetistas y el impacto de estas disposiciones negativas en las variables de actitud (estatismo, igualdad y democracia) y el voto. Los resultados apuntan a la disminución general de los sentimientos positivos hacia los partidos, especialmente el PT. También muestran efectos reducidos del antipetismo sobre las actitudes políticas, pero su fuerte influencia en los patrones de comportamiento electoral.

Palabras clave: sentimientos partidistas; antipetismo; actitudes políticas; comportamiento electoral; CSES-Eseb 2014.

\section{Résumé}

Sentiments partisans et anti-PT : contraintes et covariables

L'article examine, à l'aide de l'Enquête Brésilienne Électorale (Eseb), les sentiments sur les partis politiques (ou sentiments partisans) des électeurs brésiliens en 2014 et leurs relations avec les dimensions d'attitude et de comportement. On mettra plus particulièrement I'accent sur I'aspect anti-PT, à savoir le sentiment négatif qu'une partie croissante des électeurs brésiliens manifeste contre le Parti des Travailleurs (PT). Outre l'analyse de ces sentiments entre 2002 et 2014, nous cherchons à identifier le profil social et démographique des électeurs anti-PT et l'impact de ces sentiments négatifs sur les variables d'attitude (l'étatisme, l'égalité et la démocratie) et sur le vote. Nous avons constaté la diminution des sentiments positifs envers les partis politiques, surtout le PT. Nous avons également constaté des effets limités du sentiment anti-PT sur les attitudes politiques, mais sa grande influence sur le comportement électoral.

Mots-clés: sentiments partisans; anti-PT; attitudes politiques; comportement électoral; CSES-Eseb 2014 